\title{
WestVirginiaUniversity
}

THE RESEARCH REPOSITORY @ WVU

Graduate Theses, Dissertations, and Problem Reports

2013

\section{Brief Assessment of Distress and Pain}

\author{
Laura L. Quentin
}

Follow this and additional works at: https://researchrepository.wvu.edu/etd

\section{Recommended Citation}

Quentin, Laura L., "Brief Assessment of Distress and Pain" (2013). Graduate Theses, Dissertations, and Problem Reports. 7341.

https://researchrepository.wvu.edu/etd/7341

This Thesis is protected by copyright and/or related rights. It has been brought to you by the The Research Repository @ WVU with permission from the rights-holder(s). You are free to use this Thesis in any way that is permitted by the copyright and related rights legislation that applies to your use. For other uses you must obtain permission from the rights-holder(s) directly, unless additional rights are indicated by a Creative Commons license in the record and/ or on the work itself. This Thesis has been accepted for inclusion in WVU Graduate Theses, Dissertations, and Problem Reports collection by an authorized administrator of The Research Repository @ WVU. For more information, please contact researchrepository@mail.wvu.edu. 


\title{
Brief Assessment of Distress and Pain
}

\section{Laura L. Quentin}

\author{
Thesis submitted to the \\ Eberly College of Arts and Sciences \\ at West Virginia University \\ in partial fulfillment of the requirements for the degree of \\ Master of Science \\ in \\ Psychology \\ Daniel W. McNeil, Ph.D., Chair \\ Natalie Shook, Ph.D. \\ Aaron Metzger, Ph.D. \\ Department of Psychology \\ Morgantown, West Virginia \\ 2013
}

Keywords: assessment; anxiety; fear; pain; depression; overall negative affect Copyright 2013 Laura L. Quentin 
UMI Number: 1549773

All rights reserved

INFORMATION TO ALL USERS

The quality of this reproduction is dependent upon the quality of the copy submitted.

In the unlikely event that the author did not send a complete manuscript and there are missing pages, these will be noted. Also, if material had to be removed, a note will indicate the deletion.

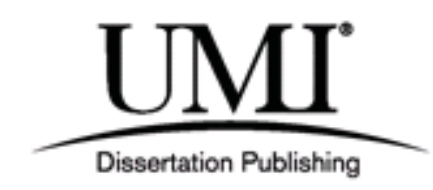

UMI 1549773

Published by ProQuest LLC (2013). Copyright in the Dissertation held by the Author.

Microform Edition (c) ProQuest LLC.

All rights reserved. This work is protected against unauthorized copying under Title 17, United States Code

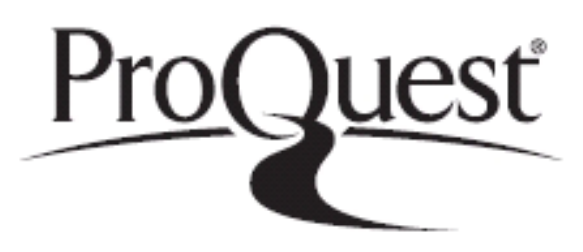

ProQuest LLC.

789 East Eisenhower Parkway

P.O. Box 1346

Ann Arbor, MI 48106 - 1346 


\section{ABSTRACT \\ Brief Assessment of Distress and Pain}

\section{Laura L. Quentin}

Pain has been conceptualized as a mixture of physical and psychological factors that are indicative of actual or potential damage to one's physical being. The experience of pain is a complex interaction of somatic, behavioral, affective, and cognitive components. Of particular interest is the growing body of literature regarding the roles that negative psychological states such as anxiety, fear, and depression have in the contribution of poorer outcomes for individuals suffering from painful conditions. Specifically, these psychological concerns can exacerbate the overall experience of pain and lead to higher rates of dysfunction and disability. Given the importance of these variables, there is a need for an efficient assessment of them in relation to pain. The present investigation focused on the development of a brief (i.e., 4-item scale) to assess fear, anxiety, depression, and overall negative affectivity in relation to the experience of pain. The study incorporated a multi-level developmental process inclusive of the use of expert judges, an undergraduate student sample $(n=415)$, and a heterogeneous chronic pain sample $(n=45)$. Principal components analyses indicated that the BADP consisted of one factor; inter-scale correlation coefficients revealed that the BADP was highly related to other measures that assess similar constructs. Intra-scale correlation coefficients indicated that the subscales of the Brief Assessment of Distress and Pain were moderately associated with each other. These data suggest the BADP is a good measure of negative affectivity related to pain. The BADP displays utility in multiple samples and is suitable for further clinical study. 
Table of Contents

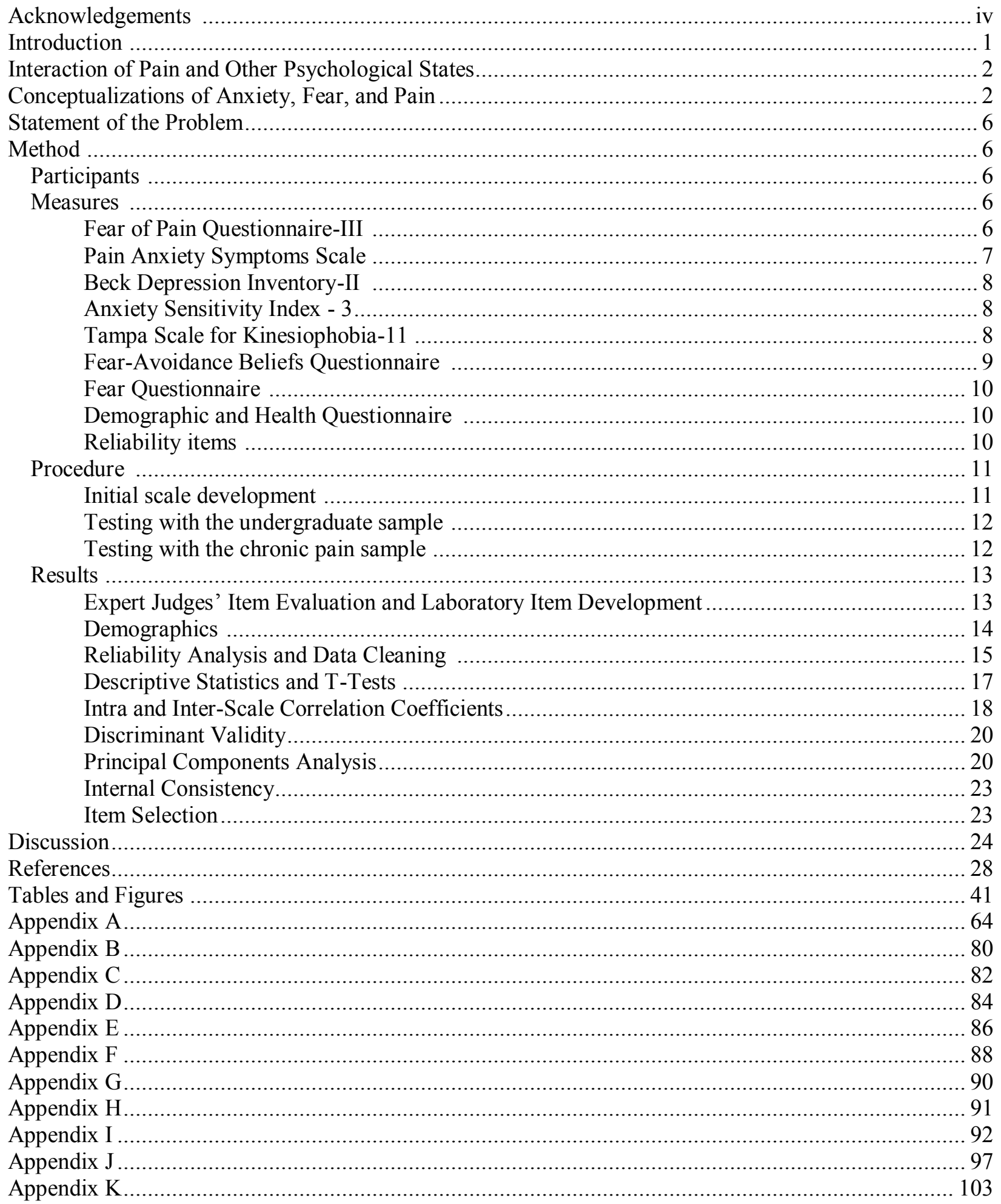




\section{BRIEF ASSESSMENT OF DISTRESS AND PAIN}

Acknowledgements

The completion of this project has been a wonderful and valuable learning experience to my career as a young professional. I am very appreciative of the time and guidance provided by the members of my committee, Drs. Daniel McNeil, Aaron Metzger, and Natalie Shook. Dr. Metzger's assistance with the statistical analyses was highly valued and appreciated. He assisted in further developing my personal comprehension and appreciation of statistics. Dr. Shook's insight and guidance regarding research and data analysis also was appreciated. Most importantly, her support was essential in completing this project. The thesis committee chair and my mentor, Dr. McNeil, is deserving of special gratitude for his time, effort, and informative feedback. Dr. McNeil's guidance, attention, and overall genuine nature and caring attitude towards the project and me were deeply appreciated.

I gratefully acknowledge all of the expert judges who reviewed the BADP items and provided informative feedback based on their knowledge and experience in the field of health and psychology. These judges included: Josh Broman-Fulks, Ph.D., Rochelle Cairns, Ph.D., Kimberly Foley, Ph.D., Richard Gross, Ph.D., Lisa Heaton, Ph.D., Brandon Kyle, Ph.D., Joan Priddy-Southern, MSN NP-C, Jeanie Sperry, Ph.D., John Sorrell, Ph.D., AJ van Wijk, Ph.D, and Kevin Vowles, Ph.D.

I also acknowledge and thank all the staff and especially, Joan Priddy-Southern, Janice Poore, and Nikki Rodgers, at Carolina Pain Institute (CPI) for graciously welcoming me into their facility as well as assisting in recruitment and data collection. Working in collaboration with the medical and research staff at CPI was insightful and gave me first-hand experience working in an interdisciplinary setting. In addition, I extend a special thank you to my mother, 
BRIEF ASSESSMENT OF DISTRESS AND PAIN

Lou Lambert, for assisting me in developing the collaborative relationship with CPI. I would also like to thank my father for all his love, encouragement, and support.

I also express gratitude to all the members of the Anxiety, Psychophysiology, and Pain Research Laboratory. Their time, effort, and insight regarding construct definition and item development were imperative to the successful completion of this project.

Lastly, I must acknowledge and thank all of my close friends and family members for their consistent love and support. They all have been a source of positivity, strength, hope, and inspiration during this project. 


\section{Brief Assessment of Distress and Pain}

Pain and emotion are intricately intertwined. Pain can be an important and helpful state, but chronic pain and its emotional components is a significant problem. Research consistently has indicated that anxiety, fear, and depression are highly related to the experience of pain and the effectiveness of treatment of pain-related conditions. Anxiety, fear, and depression, in combination with the experience of chronic pain, lead to greater impairment, disability, and poorer outcomes. Due to the high rate of comorbidity of pain and these psychological states, as well as the importance of associated negative outcomes, it is vital to develop assessment instruments in this area, in hopes of improving quality of life and treatment methodologies. While there are existing approaches to assessing negative affect associated with pain, the length of the instruments makes them impractical in in many clinical settings. Therefore, there is a need for a brief assessment which addresses negative affect, anxiety, fear, and depression, focusing on their association with pain, in one inclusive scale. In light of this aspiration and lack of a brief scale with general, over-arching items that address these psychological constructs and pain, the intent is to develop a brief scale that will examine emotional distress associated with pain.

Specifically, the brief scale will assess depression, anxiety, and fear in relation to the experience of pain directly. The ultimate goal is for this brief scale to be able to stand alone as an effective and reliable assessment for identifying individuals suffering from the experience of pain and comorbid psychological states. This assessment would be applicable in clinical settings to identify individuals who may suffer from anxiety, fear, or depression with pain in hopes of improving treatment. In addition to the following introduction, Appendix A contains a comprehensive review of the literature. 
BRIEF ASSESSMENT OF DISTRESS AND PAIN

\section{Interaction of Pain and Other Psychological States}

A significant portion of pain conditions have been found to be etiologically less directly related to physical ailments and more characteristic of psychological variables such as anxiety, anxiety sensitivity, fear, and catastrophizing cognitions (Carelton et al., 2009). These psychological variables have been found to influence the onset, duration, and intensity of pain, as well as to exacerbate its physical sensations (Beesdo et al., 2010). In fact, these psychological states also have been found to negatively affect patient responses to pain treatment (Keen, Rea, \& Aldington, 2011). Treatment of anxiety and fear also may be potentially effective in the reduction of pain (Asmundson, Norton, \& Norton, 1999). Pain also can negatively affect the psychological functioning of patients with chronic pain (Keene et al., 2011). The experience of pain can predispose individuals to develop hypervigiliance, which is associated with fear, anxiety, sleep deficits, and learned helplessness (Keene et al., 2011). Specifically, chronic pain also has been found to be comorbid with depression (Cleeland, 1986; Karoly et al., 2008; Poleshuck et al., 2010). In fact, the experience of pain over time can predispose individuals to the development of anxiety and depression (Eken et al., 2010). This phenomenon, however, does not always occur in a sequential order. Pain, anxiety, and depression may develop at similar points in time, or may predate one another. In addition to the development of anxiety and depression, the continued experience of pain over time can lead to avoidance behaviors and decreased quality of life (Karoly et al., 2008; Skevington, 1998).

\section{Conceptualizations of Anxiety, Fear, and Pain}

The view of the relations among anxiety, fear, and pain has changed over time. Initially, pain and fear were viewed as completely separate constructs with no common overlap (McNeil \& van Wijk, 2005). As research advanced, experts within the field began to view the relationship 
BRIEF ASSESSMENT OF DISTRESS AND PAIN

between fear and pain as unidirectional (McNeil \& van Wijk, 2005). Specifically, fear was conceptualized as having a direct impact on the experience of pain (McNeil \& van Wijk, 2005). This conceptualization is evident with the development of the Gate-Control Theory, which focuses on fear and other negative emotional states as being a factor for contributing to a more debilitating experience associated with pain (Melzack \& Wall, 1965). Bolles and Fanselow (1980) later developed the Perceptual-Defensive-Recuperative theory. This theory, which is based on evolutionary principles, posited fear and pain as competing forces rather than as interacting in a compound nature. Bolles and Fanselow (1980) believed that fear and pain inhibit the expression of the other state. Later, experts began to believe that fear and pain were in fact highly correlated and shared similarities of expression (McNeil \& van Wijk, 2005). The current model involves an interaction between not only fear and pain, but also anxiety. Specifically, fear, anxiety, and pain are viewed as mutually interacting with each other, thus affecting the expression and behavior associated with the experience of pain (McNeil \& van Wijk, 2005). It is this model that will be used as a basis for developing a brief assessment, which will examine the constructs of pain, anxiety, fear, and depression.

Overall, fear, anxiety, depression, and overall negative affectivity all are related to the experience of pain and have been shown to exacerbate the experience of pain. The associations between these emotional states and pain are not necessarily linear in nature. The associations among fear, anxiety, depression, overall negative affectivity, and pain are multi-directional and complex. In general however, negative emotional states, in combination with chronic pain, lead to greater disability, functional impairment, and poorer health outcomes. 
BRIEF ASSESSMENT OF DISTRESS AND PAIN

\section{Statement of the Problem}

Numerous assessment instruments have been developed to evaluate relations among fear, anxiety, and pain including Fear of Pain Questionnaire-III (FPQ-III), Pain Anxiety Symptoms Scale (PASS), Fear-Avoidance Beliefs Questionnaire (FABQ), and Tampa Scale for Kinesiophobia (TSK-11) (McCraken, Zayfert, \& Gross, 1992; McNeil \& Rainwater, 1998; Wadell, Newton, Henderson, Somerville, \& Main, 1993; Woby, Roach, Urmston, \& Watson, 2005). These measures have intermixed the constructs of fear and anxiety, failing to differentiate between them and pain. In addition, other important emotional states that are commonly associated with pain, such as depression, have been neglected. These limitations highlight the need for an assessment that measures common affective states in relation to pain. Additionally, assessing overall negative affect as a general construct may be fruitful in relation to the study of emotion and pain. This gap in the literature highlights the need for a short assessment scale which will evaluate depression, fear, and anxiety, in relation to the experience of pain. Currently, no scale exists that assesses all three of these constructs together relative to pain. The development of a short assessment that examines negative emotional states and pain may assist in the early detection of individuals with comorbid conditions.

In healthcare settings, the length and scoring demands of a screening or other assessment are crucial in relation to utility (Krebs et al., 2009). Due to the length of these self-report measures, many are not incorporated into standard protocols in healthcare settings (Krebs et al., 2009). Longer assessments tend to have poorer response rates which can lead to inaccurate statistical conclusions relating to the constructs of interest (Faragher, Cooper, \& Cartwright, 2004). Shorter instruments, however, can be easily implemented into busy, fast-paced healthcare settings in which time of both the patient and staff is of the concern. A brief assessment is less likely to 
BRIEF ASSESSMENT OF DISTRESS AND PAIN

burden the patient taking the assessment, and the staff who must score and analyze the results. A short measure can serve as a useful and practical screener to identify individuals who may be at greater risk for comorbid conditions thus leading to improved treatment and referrals to appropriate providers.

There are several issues that should be considered when constructing a short assessment. The length of an instrument can directly affect the reliability of the scale such that longer assessments tend to be more valid than short assessments (Furr \& Bacharach, 2008). Some argue that single item assessments may be less sensitive, but through careful examination and analysis, can still be valid (Bowling, 2005). Shorter assessments have been found to possess greater validity than lengthier assessments (Bowling, 2005). Single item assessments with adequate reliability and validity have been tested and incorporated in multiple health-based surveys (Bowling, 2005). Several scales (i.e., Visual Analogue Scale and single item quality of life assessment) have been found to possess strong psychometric properties and are widely utilized (Bowling, 2005). Advantages of single item scales include simplicity and decreased burden on the participants (Bowling, 2005). Omnibus items on short assessments can be criticized for being less sensitive, but these items can be highly valid.

The major goal of this study is to create a short scale which assesses each of the three constructs (fear, anxiety, and depression) in relation to the experience of pain, and has an overall, omnibus item which would be representative of overall negative affectivity towards the experience of pain. The availability of such an assessment would ease the administration process as well as the scoring procedure, positively impacting both clinicians and patients. Overall implications of the development of this type of instrument include identification of at risk 
BRIEF ASSESSMENT OF DISTRESS AND PAIN

individuals in health-care settings, which may lead to improved preventive treatment and treatment methodologies.

\section{Method}

\section{Participants}

Individuals in this study were 500 introductory Psychology undergraduate students at West Virginia University and 60 patients seeking treatment for a variety of pain related conditions at a pain clinic in Winston-Salem, NC. Sample sizes were based on recommendations by Costello and Osborne (2005) and Lingard and Rowlinson (2005). The recommendations indicate a 10:1 ratio of participants to items is sufficient to produce correct solutions. The inclusion criterion specified that all participants must be 18 years of age or older and must be able to read, write, and comprehend the English language. Exclusion criteria included the presence of psychotic symptomatology or a pervasive developmental disorder. Procedures adhered to American Psychological Association ethical guidelines for the proper treatment of human subjects, as well as the informed consent process and approval of the research by the Institutional Review Board at West Virginia University.

\section{Measures}

Fear of Pain Questionnaire-III. The FPQ-III is a measure that assesses fear of pain (McNeil \& Rainwater, 1998). The instrument consists of 30 items which examine three domains of pain: Minor, Medical, and Severe pain (McNeil \& Rainwater, 1998). Items are scored on a 5 point Likert type scale ranging from $1=$ Not at all to $5=$ Extreme (McNeil \& Rainwater, 1998). Items are scored by summing subscales scores (McNeil \& Rainwater, 1998). The FPQ-III possesses high test-retest reliability $(r=.92)$ and high internal consistency $(\alpha=.74)($ McNeil \& Rainwater, 1998). Each subscale also possesses high internal consistency, Severe Pain $(\alpha=.88)$, 
BRIEF ASSESSMENT OF DISTRESS AND PAIN

Minor Pain $(\alpha=.87)$, and Medical Pain $(\alpha=.87)$, and strong test-retest correlations $(.69<r<$

.76) indicating stability over time (McNeil \& Rainwater, 1998); please refer to Appendix C.

Pain Anxiety Symptoms Scale. The PASS assesses the experience of fear and anxiety in relation to the experience of pain (McCraken et al., 1992). The measure consists of 21 items which assess four domains of fear and anxiety and their relationship to pain: Somatic Anxiety, Cognitive Anxiety, Fear, and Escape or Avoidance (McCraken et al., 1992). Items are scored on a 6 point Likert type scale ranging from $0=$ Never to $5=$ Always (McCraken et al., 1992). Items are summed for a total score indicative of overall fear/anxiety in relation to pain (McCraken et al., 1992). The overall measure possesses high internal consistency $(\alpha=.94)$ (McCraken et al., 1992). Subscales also are summed for a specific indication of degree of anxiety or fear (McCraken et al., 1992). Each subscale also possesses high internal consistency, Somatic Anxiety $(\alpha=.89)$, Cognitive Anxiety $(\alpha=.87)$, Fear $(\alpha=.85)$, and Escape or Avoidance $(\alpha=$ .81) (McCraken et al., 1992). As reported by McCraken et al. (1992), the PASS was found to have sound concurrent validity in comparison to the Beck Depression Inventory $(r=.57)$, the Multidimensional Pain Inventory $(.32<r<.39)$, and the Pain Disability Index $(r=.45)$ for patient outcome variables such as disability and depression; please refer to Appendix D.

Beck Depression Inventory-II (BDI-II). This scale is a predominant instrument for assessing overall severity of depression (Anastopoulos \& Shelton, 2001; Beck, Steer, \& Brown, 1996). The BDI-II is the updated revision of the original BDI (Anastopoulos \& Shelton, 2001; Beck et al., 1996). The BDI-II is a self-report instrument that contains 21 items on a 4 point Likert type scale (Anastopoulos \& Shelton, 2001; Beck et al., 1996). The BDI-II matches well to the DSM-IV-TR criteria which assess the cognitive, somatic, and affective components of depression (Anastopoulos \& Shelton, 2001; Beck et al., 1996). The two subscales that compose 
BRIEF ASSESSMENT OF DISTRESS AND PAIN

the BDI-II are the Cognitive-Affective factor and the Somatic factor (Beck et al., 1996; Storch, Roberti, \& Roth, 2004). The BDI-II has sound psychometric properties in addition to being easy to administer and score (Anastopoulos \& Shelton, 2001; Beck et al., 1996). The BDI-II had strong test-retest reliability $(.74<r<.96)$ in a student client sample, outpatient sample, and hearing impaired sample (Sprinkle et al., 2002). The BDI-II also has high internal consistency $(r$ $<$.90). Each subscale also possesses high internal consistency, Cognitive-Affective factor $(r<$ $.87)$ and the Somatic factor $(r<.74)$ (Storch et al., 2004). The BDI-II also has strong convergent validity with the BDI $(.84<r<.93)$, the Hamilton Psychiatric Rating Scale for Depression, the Beck Hopelessness Scale $(.68<r<.71)$, the Speilberger's State Trait Anxiety Inventory Anxiety factor $(.52<r<.69)$, and the Speilberger's State Trait Anxiety Inventory Depression factor $(.57$ $<r<.76$ ) (Sprinkle et al., 2002; Storch et al., 2004). The BDI-II is not included in the appendices due to copyright restrictions.

Anxiety Sensitivity Index-3. The ASI-3 assesses a high order factor of anxiety sensitivity (Taylor et al., 2007). The higher order factor of anxiety sensitivity is composed of 3 lower order factors which are cognitive, social, and physiological concerns (Taylor et al., 2007). The ASI-3 consists of 18 items which are scored on a 5 point Likert type scale $(0=$ very little to $4=$ very much) (Taylor et al., 2007). The internal consistency of the ASI-3 is moderate to high $(.73<\alpha<$ .91) (Taylor et al., 2007). The ASI-3 also has been shown to have adequate convergent, discriminant, and criterion-related validity (Taylor et al., 2007); please refer to Appendix E.

Tampa Scale for Kinesiophobia-11. The TSK-11 assesses the pain related fear of movement of re-injury in chronic back pain patients (Woby et al., 2005). It is the shortened version of the original Tampa Scale for Kinesiophobia (Woby et al., 2005). The TSK-11 is an 11 item measure that is scored on a 4 point Likert type scale ranging from strongly disagree to 
BRIEF ASSESSMENT OF DISTRESS AND PAIN

strongly agree (Woby et al., 2005). Higher scores on the TSK-11 are indicative of greater fear of movement or re-injury (Woby et al., 2005). The TSK-11 has moderate to high internal consistency $(\alpha=.79)$ (Woby et al., 2005). The TSK-11 also demonstrates high test-retest reliability $(r=.82)$ as depicted by intraclass correlation analyses (Woby et al., 2005). The TSK11 also has construct, concurrent, and predictive validity (Woby et al., 2005). Reductions in the scores on both the TSK and TSK-11 were associated with reductions in overall disability in chronic lower back pain sufferers (Woby et al., 2005). The TSK-11 has been found to be comparable to the original TSK $(r=.93)$ (Woby et al., 2005). The TSK-11 instructions were altered to make them more applicable to an undergraduate student sample; please refer to Appendix F.

Fear-Avoidance Beliefs Questionnaire. The FABQ assesses individuals' beliefs about how work related tasks and physical activity affected their degree of pain (Waddell et al., 1993). The FABQ focuses on the degree to which an individual reports fear of an activity and avoids it, which has been associated with work related losses and decreased physical activity (Waddell et al., 1993). The FABQ has two factors, fear-avoidance beliefs related to back pain and work and fear-avoidance beliefs about general physical activity (Waddell et al., 1993). The FABQ is a 16 item self-report assessment that is scored on a 7 point Likert type scale ranging from strongly disagree to strongly agree (Waddell et al., 1993). The FABQ demonstrates strong test-retest reliability $(.88<\mathrm{r}<.95)$ over a 48 hour testing period (Waddell et al., 1993). In a sample of 184 lower back pain patients, the two factors on the FABQ the fear-avoidance beliefs relating to work and the fear-avoidance beliefs about physical activity scale accounted for $26 \%$ of the variance associated with loss of work, $23 \%$ of the variance of disability after controlling for pain 
BRIEF ASSESSMENT OF DISTRESS AND PAIN

severity (Waddell et al., 1993). The FABQ instructions were altered to make them more applicable to an undergraduate student sample; please refer to Appendix G.

Fear Questionnaire. The FQ is a 17 item self-report measure that assesses the degree of severity of several anxiety-related phobias (Marks \& Mathews, 1979). A few of the phobias assessed on the FQ are agoraphobia and social phobia (Marks \& Mathews, 1979). The FQ is scored on a 9 point Likert type scale $(0=$ Would not avoid it to $8=$ Always avoid it $)$ (Marks $\&$ Mathews, 1979). For this study, the agoraphobic scale was utilized to determine divergent validity from the Brief Assessment of Distress and Pain. The agoraphobia scale (Ag) of the FQ ranges from a score of 0 to 40 (Marks \& Mathews, 1979). The internal consistency of agoraphobia scale of the FQ is moderate to high $(.71<\alpha<.83)$ in a sample of participants with diagnosed anxiety disorders (Marks \& Mathews, 1979). The FQ-AG was included only in the undergraduate assessment battery to examine the discriminant validity between the FQ-AG and the BADP; please refer to Appendix H.

Demographic and Health Questionnaire. This instrument asked for participants' sex, age, ethnicity, social economic status, education level, employment status, and income. In addition, the demographic questionnaire asked for participants' presence of pain, severity of pain, pertinent physical injuries or illnesses (e.g., broken bones, surgeries, sprains, migraines), current psychotropic, narcotic or anti-inflammatory medication usage, and past experiences of severe or chronic pain, significant injuries, and childbirth. A general health item from the Health SurveyShort Form was included in the demographic questionnaire for the pain sample (Ware, Kosinski, \& Keller, 1996); please refer to Appendices I and J.

Reliability items. There were four items added to the assessment battery for the undergraduate sample (J. Patrick, personal communication, March, 2013). These types of items 
BRIEF ASSESSMENT OF DISTRESS AND PAIN

have been incorporated in previous studies on SONA. These items were included to check that each participant was adequately reading and reporting to the items that composed the assessment battery; please refer to Appendix K.

\section{Procedure}

Initial scale development. Construct definitions for anxiety, fear, depression, negative affect, and pain were developed by members (i.e., one faculty member, five graduate students, and three undergraduate students) of the Anxiety, Physiology, and Pain research laboratory (APPL) at West Virginia University. Items also were designed, critiqued, and analyzed in APPL laboratory. These definitions were based on previous definitions in the literature and expert opinion. Academics, health, and mental health professionals $(n=11)$ who specialize in the field of emotion and pain were selected to serve as expert judges based on the criteria outlined by DeVellis (2003). The list of expert judges that were selected and asked to participate in the development of the BADP was generated in the APPL laboratory. If the judge agreed to participate, he or she was provided with an operational definition of each construct and the item pool, please refer to Appendix B. Expert judges rated each item as essential, useful but not essential, or not necessary based on the criteria outline by Lawshe (1975).

After feedback from the expert judges, the best items were selected for each construct comprising the Brief Assessment of Distress about Pain scale. A total of 20 items was retained for the version of the BADP that was administered to the undergraduate sample and the pain sample. Readability was assessed through the Flesch-Kincaid readability tests (i.e., readability ease and grade level) to ensure that the reading level is at a sixth grade level or below. The Flesch-Kincaid readability tests examine choice of words, length of sentences, and sentence structure to determine the overall comprehension level required to understand the content of the 
BRIEF ASSESSMENT OF DISTRESS AND PAIN

assessment, and assigns a grade level to the document (Kincaid, Fishburne, Rogers, \& Chissom, 1975).

Testing with the undergraduate sample. Undergraduate participants from a variety of Psychology courses in the present study were volunteers who were recruited through advertisements within the Psychology Department at West Virginia University. All participants gave written informed consent, completed a demographic questionnaire, and a battery of assessments inclusive of the Brief Assessment of Distress about Pain.

The undergraduate sample was administered a 20 item version of the Brief Assessment of Distress and Pain scale. The undergraduate sample $(N=500)$ was administered the demographic questionnaire and the battery of assessments on a computer through SONA, a web-based online survey system which has a licensed contract with West Virginia University. The battery of assessments included the FPQ-III, PASS, BADP, BDI-II, ASI-3, TSK-11, FQ-AG, demographic questionnaire, and the FABQ which were presented in the order listed.

Testing with the chronic pain sample. A sample of 60 chronic pain patients also was recruited on a volunteer basis in a pain clinic in Winston-Salem, North Carolina. The purpose of incorporating both samples was to compare responses on the assessments, especially the BADP, as well as to ensure that the final version of the BADP will be applicable to a broad, generalized sample. The pain sample also was administered the 20 item version of the Brief Assessment of Distress and Pain to maximize the probability of selecting the top 4 items for the final version of the Brief Assessment of Distress and Pain. The final assessment was developed after the administration of the 20 item version to the undergraduate and pain samples and the scale had been condensed through confirmatory factor analysis and inspection of items. All participants in the pain sample were provided only paper and pencil formats of the battery of assessments 
BRIEF ASSESSMENT OF DISTRESS AND PAIN

inclusive of the Brief Assessment of Distress and Pain. The presentation order of the assessments in the battery was: demographic questionnaire, 20-item BADP, FPQ-III, PASS, BDI-II, and a demographic and health questionnaire. These assessments were selected to be included in the battery because they assessed the three constructs of interest (i.e., fear, anxiety, and depression). A shorter battery of assessments was selected due to time constraints as well as in effort to reduce burden and fatigue on the chronic pain participants. Upon completion of the assessment battery, participants were thanked, debriefed, and paid \$20 for their time and effort.

\section{Results}

\section{Expert Judges' Item Evaluation and Laboratory Item Development}

Construct definitions for anxiety, fear, depression, and overall negative affectivity were examined in the literature as well as discussed within the APPL laboratory. Items were generated within the laboratory and reduced to 20 items per construct through discussion and item analysis. All items were subjected to Flesh-Kincaid analyses to determine the grade level of readability of each item, as shown in Tables 1-2. A list of 16 expert judges who specialize within the fields of pain and emotion (i.e., physicians and health psychologists) was generated after the item pool had been condensed. Each judge was contacted via email with a brief description of the project, instructions on how to evaluate the each item, and the list of the 60 total items; of the 16 judges who were contacted, $11(68.8 \%)$ responded. In addition, each judge was provided a section asking for specific feedback on each item. Expert judges rated each item as (a) essential, (b) useful but not essential, or (c) not necessary. To examine the agreement among each of the judges of each item, the content validity ratio (CVR) in addition to other factors were assessed for each item (Lawshe, 1975). The CVR formula that is used for evaluating each item is CVR= $\left(n_{e}-N / 2\right) /(N / 2)$ where " $n_{e}$ " represents the number of expert judges that rated an item as 
BRIEF ASSESSMENT OF DISTRESS AND PAIN

essential and " $\mathrm{N}$ " representing the total number of expert judges that rated an item. Values range from -1 to +1 with more positive values indicating ratings of essential. Further, more positive scores also indicate a greater degree of content validity. The number of judges included affects the CVR, such that in the case of 11 judges, only one can note it other than essential and the item meet criterion. Subsequently, ratings of essential or useful but not essential were considered in the $\mathrm{n}_{\mathrm{e}}$ variable in the CVR calculation. Items that did not meet 0.75 criteria outline by Lawshe (1975) were deleted or revised. Items that possessed the highest CVR with great ratings of essential or useful but not essential were selected. Based on the judges' ratings and recommendations, and the APPL laboratory suggestions, a 20 item version of the BADP was developed to administer to the undergraduate and pain samples; please refer to Tables 3-6.

\section{Demographics}

Undergraduate sample. A total of 503 undergraduate students was collected at West Virginia University; please refer to Figure 1. The mean age of the undergraduate sample was 19.9 years $(\mathrm{SD}=1.8)$. The majority of the undergraduate sample was single $(56.5 \%)$. The ethnic composition of the sample was predominantly Caucasian (91.9\%) followed by African-American (2.9\%), Hispanic/Latino (0.7\%), American Indian (1.0\%), Other (0.5\%), and Mixed (3.0\%). In relation to SES, a portion of the undergraduate sample held part-time employment (42.0\%) or were unemployed (37.9\%). The rest of the sample held full-time employment $(5.0 \%)$, volunteered $(2.4 \%)$, or listed “other” $(12.7 \%)$ for employment. Their families' income was grouped as follows: $\$ 0-20,000(7.2 \%), \$ 20-40,000(13.2 \%), \$ 40-60,000(16.1 \%), \$ 60-80,000$ (14.9\%), $\$ 80-100,000(12.3 \%), \$ 100,000$ or more $(26.7 \%)$.

Chronic pain patient sample. A total of 60 chronic pain patients was collected at Carolina Pain Institute; please refer to Figure 2. The mean age of the pain sample was 54.4 years 
BRIEF ASSESSMENT OF DISTRESS AND PAIN

$(\mathrm{SD}=11.6)$ and the sample was predominantly female $(62.2 \%)$. The ethnic composition of the sample was predominantly Caucasian (86.7\%) followed by African-American (4.4\%), Hispanic/Latino (2.2\%), American Indian (2.2\%), and Other (4.4\%). The majority of the sample self-perceived themselves as disabled $(60.0 \%)$. The rest of the sample held full-time employment (15.6\%), part-time employment (4.4\%), volunteered (2.2\%), were unemployed (6.7\%), or listed “other" (8.9\%) for employment. The chronic pain participants' annual income was grouped as follows: $\$ 0-20,000$ (35.6\%), \$20-40,000 (24.4\%), \$40-60,000 (13.3\%), \$60-80,000 (11.1\%), $\$ 80-100,000(6.7 \%), \$ 100,000$ or more $(8.9 \%)$.

\section{Reliability Analysis and Data Cleaning}

Undergraduate sample. To ensure high quality data for the undergraduate sample, seven reliability items were included in the online survey. Participants were required to select a specific answer option or enter a specific code on four of the seven seven items. The other three items were taken from the FPQ-III (i.e., item 10), TSK-11 (i.e., item 3), and the BDI-II (i.e., item 8) assessments. One item from each of these scales was repeated at the end of the scale within the online survey.

To determine the reliability of each participant's responses, duration spent taking the online assessment battery was examined first. The mean duration was found to be 25.8 minutes with a standard deviation of 11.9 minutes. The data were examined for trends, and inspected in terms of 1 and 2 standard deviation cut off scores. It was determined that a cut-off score of 13minutes would be optimal. Specifically, any individual who spent less than 13 minutes taking the survey was eliminated, and the one outlier of 133 minutes was removed from the data set.

Decline to answer options on specific demographic items were examined next.

Frequencies for demographic items were calculated and reviewed. Participants who responded 
BRIEF ASSESSMENT OF DISTRESS AND PAIN

to demographic items with three or less "decline to answer" selections were removed, in addition to individuals who declined to answer on specific dichotomous pain items (i.e., "yes" or "no" to the presence of pain). After these items were removed, a total of 448 participants was left in the sample.

The seven reliability items were examined and divided such that those that required a specific response were examined together, and those that were duplicated assessment items were examined together. The three reliability items that required a specific response were coded for accuracy. Coded items were then summed across reliability items. Initially, any participant who missed an item on this grouping of reliability items or selected decline to answer or not applicable answer options was considered for removal which could have left a sample of $\mathrm{N}=$ 414. In combination with the previously decided upon criteria for the other set of reliability items (i.e., assessment reliability items), this criterion was found to be too stringent, which would have led to a sample of 392. A final decision was made to retain any individual who missed just one of the four non-repeated assessment reliability items. All individuals who missed more than one of these reliability items or selected decline to answer or not applicable were removed, leading to a final useable sample of 442 .

There was a total of three duplicated assessment items from the BDI-II (i.e., item 8), FPQ-III (i.e., item 10), and the TSK-11 (i.e., item 3) which were examined last. Each duplicated item occurred at the end of the same assessment section. Due to each of the assessments having different scales in relation to their answer options, different criteria were used to code each assessment. The BDI-II and the TSK-11 are both constructed as 4 point scales whereas the FPQIII was constructed as a 5 point scale. It was decided that individuals would be allowed to vary by 1 point on their selected answer options on the BDI-II and the TSK-11 and by 2 points on the 
BRIEF ASSESSMENT OF DISTRESS AND PAIN

their selected answer options on the FPQ-III. Any individual who did not meet the decided upon criteria was excluded which led to a final sample of 416 . Out of the 416 individuals left, one individual declined to answer on multiple items on the Brief Assessment of Distress and Pain (BADP) and was eliminated leaving a final total sample of 415; please refer to Figure 1.

Chronic pain sample. In relation to the pain sample, seven chronic pain patients missed at least one item or more on the assessment battery or failed to provide a specific response option. These seven individuals were removed from the final data set, bringing the total sample to a total of 53. After further examination, eight chronic pain patients required assistance with completing the battery of assessments. Because of the possibility that these individuals may have altered their responses due to the presence of another individual, these eight individuals were also removed from the final data set. One of these eight individuals also missed at least one item or failed to provide a specific response option. Two other participants provided highly discrepant answers and were thus removed from the final data set due to inconsistent responding. After cleaning the data, the final sample consisted of 45 chronic pain patients; please refer to Figure 2.

\section{Descriptive Statistics and $t$-Tests}

Means and standard deviations for the total and subscale scores of the BADP, FPQ-III, PASS, and BDI-II were examined in undergraduate sample and the chronic pain sample. Overall, the pain sample was elevated on most of the measures (i.e., BADP Depression subscale, BADP Overall Negative Affectivity subscale, BADP total score, BDI-II total score, all subscales of the FPQ-III, and the Escape Avoidance subscale of the PASS) as compared to the undergraduate sample; please refer to Table 7.

Independent $t$-tests were conducted to determine if there were any significant differences between the subjects who were removed from those that were retained in the undergraduate and 
BRIEF ASSESSMENT OF DISTRESS AND PAIN

pain samples for the following variables: age, BADP Overall Negative Affect subscale, and BADP total score. Participants who were removed $(\mathrm{M}=19.9, \mathrm{SD}=1.6)$ from the undergraduate sample did not differ significantly on age $(t(499)=.05, p=.96)$ from participants who were kept $(\mathrm{M}=19.9, \mathrm{SD}=1.8)$. The participants who were removed $(\mathrm{M}=6.4, \mathrm{SD}=4.1)$ also did not differ from those who were retained $(\mathrm{M}=6.1, \mathrm{SD}=4.6)$ on the BADP Overall Negative Affect subscale $(t(499)=.57, p=.57)$. The results were similar for the BADP total scale $t(499)=.33$, $p=.75)$ for those who were removed $(\mathrm{M}=26.4, \mathrm{SD}=14.7)$ as compared to those who were retained $(\mathrm{M}=25.8, \mathrm{SD}=16.3)$.

Participants who were removed $(M=52.7, \mathrm{SD}=13.9)$ from the pain sample did not differ significantly from those retained $(\mathrm{M}=54.4, \mathrm{SD}=11.6)$ on age $(t(58)=.47, p=.64)$. Those who were removed $(\mathrm{M}=9.7, \mathrm{SD}=6.6)$ also did not differ from those retained $(\mathrm{M}=8.4$, $\mathrm{SD}=6.6)$ on the BADP Overall Negative Affect subscale $(t(58)=-.66, p=.51)$. This same pattern was found for the BADP total scale $t(58)=-.33, p=.74)$ for those who were removed $(\mathrm{M}=34.9, \mathrm{SD}=25.7)$ as compared to those retained $(\mathrm{M}=32.4, \mathrm{SD}=24.5)$.

\section{Intra and Inter-Scale Correlation Coefficients}

Data from all 20 items of the BADP provided by the 415 undergraduate student participants, the 45 chronic pain participants, and the combined samples were subjected to intraand inter-correlation analyses; please refer to Tables 8-15. Pearson correlation coefficients were examined within the hypothesized subscales of the BADP as well as across other assessments scales (i.e., BDI-II, PASS, and the FPQ-III).

Intra-correlations indicated a high degree of relation among all scales and items. Specifically, moderate to highly association was found among all the subscales of the BADP, refer to Tables 8-11. In terms of inter-correlation coefficients, the subscales of the BADP were 
BRIEF ASSESSMENT OF DISTRESS AND PAIN

found to be related to the majority of the subscales and full scales of the other assessments included in the battery.

The BADP fear subscale was slightly to moderately related to the BDI-II, the FPQ-III's Minor Pain, Severe Pain, Medical/Dental subscales, and the FPQ-III total scale $(0.38<r<0.74)$. The fear subscale of the BADP was found to be moderately to highly associated with the PASS Fear subscale, the PASS Cognitive Anxiety, Escape Avoidance, Physiological Anxiety subscales, and the PASS total scale $(0.49<r<0.82)$; please refer to Table 12 .

The BADP anxiety subscale was slightly to moderately related to the BDI-II, the FPQIII's Minor Pain, Severe Pain, Medical subscales, and the FPQ-III total scale $(0.37<r<0.70)$. The anxiety subscale of the BADP was found to be moderately to highly associated with the PASS Fear subscale, the PASS Cognitive Anxiety, Escape Avoidance, Physiological Anxiety subscales, and the PASS total scale $(0.48<r<0.82)$; please refer to Table 13 .

The depression subscale was slightly to moderately related to the BDI-II, the FPQ-III's Minor Pain, Severe Pain, the Medical subscales, the FPQ-III total scale, the PASS Escape Avoidance, and the PASS Physiological Anxiety subscales $(0.23<r<0.73)$. The depression subscale of the BADP was found to be moderately to highly associated with the PASS Fear, Cognitive Anxiety subscales, and the PASS total scale $(0.53<r<0.85)$; please refer to Table 14 .

The BADP overall negative affect subscale was low to moderately related to the BDI-II, the FPQ-III's Minor Pain, Severe Pain, Medical subscales, and the FPQ-III total scale $(0.25<r<$ 0.74). The overall negative affect subscale of the BADP was found to be moderately to highly associated with the PASS Fear, Cognitive Anxiety, Escape Avoidance, Physiological Anxiety subscales, and the PASS total scale $(0.59<r<0.85)$; please refer to Table 15. 
BRIEF ASSESSMENT OF DISTRESS AND PAIN

\section{Discriminant Validity}

As planned, the FQ-Ag was utilized only with the undergraduate sample. Correlations

between the BADP subscales, and the BADP total score, and the FQ-Ag were low $(.25<r<.31)$ indicating some degree of discriminant validity; please refer to Table 16.

\section{Principal Components Analysis}

Exploratory factor analysis (i.e., Principal Components Analysis or PCA) was conducted on the 20 item version of the BADP for the undergraduate sample and the combined sample (i.e., pain sample and the undergraduate sample). A PCA was not conducted on the pain sample alone due to the limited power and the number of total participants $(N=45)$. For all PCA analyses, a varimax rotation was utilized.

For the undergraduate sample, the Kaiser-Meyer-Olkin measure verified the sampling adequacy for the analysis, $\mathrm{KMO}=.97$, which is listed as within the "superb" range (Field, 2009). The combination of the KMO and Bartlett's test of sphericity indicated that the data were adequate to conduct a PCA. Bartlett's test of sphericity $\chi^{2}(190)=6687.45, p<.001$, indicated that correlations between items were sufficiently large for PCA. An initial analysis was conducted to determine eigenvalues for each component in the data. Three components had eigenvalues over Kaiser's criterion of 1 and in combination explained $70.04 \%$ of the variance. The first component accounted for $58.91 \%$ of the total variance with an eigenvalue of 11.78 The second component only accounted for $6.04 \%$ of the total variance with an eigenvalue of 1.21 . The third component accounted for only $5.09 \%$ of the total variance with an eigenvalue of 1.02 . The scree plot, on the other hand, displayed what appeared to be predominately a one component scale. The recommended cut-point of .40 was utilized for the examination of the factor loadings of the BADP items. This component appears to be related to overall negative affectivity in 
BRIEF ASSESSMENT OF DISTRESS AND PAIN

relation to the experience of pain. BADP items $1,3,4,5,11,12,14,16$, and 20 did not crossload on the rotated component matrix. On the rotated component matrix, it appeared that items from the anxiety and fear subscales clustered together, whereas the depression and overall negative affectivity subscales clustered together. After examination of the rotated component matrix and the scree plot, an additional PCA was conducted on these items to determine whether there were two separate components (i.e., one component consisting of fear and anxiety and the other of depression and overall negative affectivity). After conducting the secondary PCA, only one component emerged; please refer to Table 17 for the factor loadings of the individual BADP items.

To further examine the two component structure, a PCA was conducted on BADP items $1,3,4,5,11,12,14,16$, and 20 with a forced three component structure. The Kaiser-MeyerOlkin measure verified the sampling adequacy for the analysis, $\mathrm{KMO}=.97$, which is listed as within the "superb" range (Field, 2009). The combination of the KMO and Bartlett's test of sphericity indicated that the data were adequate to conduct a PCA. Bartlett's test of sphericity $\chi^{2}$ $(190)=6687.45, p<.001$, indicated that correlations between items were sufficiently large for PCA. An initial analysis was conducted to determine eigenvalues for each component in the data. The first component had an eigenvalue over Kaiser's criterion of 1 and explained $58.91 \%$ of the variance. The second component explained only $6.04 \%$ of the variance. The third component explained only $5.09 \%$ of the variance. The scree plot confirmed a predominately one factor scale. In examining the rotated component matrix, anxiety and fear items still clustered together whereas depression and overall negative affectivity clustered together. Given the large sample size, the scree plot, and Kaiser's criterion, one component was retained for the undergraduate sample. 
BRIEF ASSESSMENT OF DISTRESS AND PAIN

For the combined sample, the Kaiser-Meyer-Olkin measure verified the sampling adequacy for the analysis, $\mathrm{KMO}=.97$, which is listed as within the "superb" range (Field, 2009). The combination of the KMO and Bartlett's test of sphericity indicated that the data were adequate to conduct a PCA. Bartlett's test of sphericity $\chi^{2}(190)=8070.92, p<.001$, indicated that correlations between items were sufficiently large for PCA. An initial analysis was conducted to determine eigenvalues for each component in the data. Two components had eigenvalues over Kaiser's criterion of 1 and in combination explained $67.76 \%$ of the variance. The first component accounted for $61.90 \%$ of the total variance with an eigenvalue of 12.38 . The second component only accounted for $5.86 \%$ of the total variance with an eigenvalue of 1.17 . The scree plot, on the other hand, displayed what appeared to be predominately a one component scale. The recommended cut-point of .40 was utilized for the examination of the factor loadings of the BADP items. This component appears to be related to overall negative affectivity in relation to the experience of pain. BADP items $1,4,6,7,11,12,13,14,16$, and 17 did not crossload on the rotated component matrix. An additional PCA was conducted on these items to determine whether there were in fact two separate components (i.e., one component consisting of fear and anxiety and the other of depression and overall negative affectivity) in the scale. After conducting the secondary PCA, only one component emerged; please refer to Table 18 for the factor loadings of the individual BADP items.

To further examine the two component structure, a PCA was conducted on BADP items $1,4,6,7,11,12,13,14,16$, and 17 with a forced two factor structure. The Kaiser-Meyer-Olkin measure verified the sampling adequacy for the analysis, $\mathrm{KMO}=.93$, which is listed as within the "superb" range (Field, 2009). The combination of the KMO and Bartlett's test of sphericity indicated that the data was adequate to conduct a PCA. Bartlett's test of sphericity $\chi^{2}(45)=$ 
BRIEF ASSESSMENT OF DISTRESS AND PAIN

2955.11, $p<.001$, indicated that correlations between items were sufficiently large for PCA. An initial analysis was conducted to determine eigenvalues for each component in the data. One component had an eigenvalue over Kaiser's criterion of 1 and explained $60.73 \%$ of the variance. The next component almost reached Kaiser's criterion of 1 (.97) and explained only $9.74 \%$ of the variance. The scree plot appeared to confirm a one factor scale. In examining the rotated component matrix, anxiety and fear items again clustered together whereas depression and overall negative affect clustered together. Given the large sample size, the scree plot, and Kaiser's criterion, one component was retained for the combined sample.

\section{Internal Consistency}

The Fear, Anxiety, Depression, and Overall Negative Affectivity subscales for the undergraduate sample were found to have high reliability with a Cronbach's .88< $\alpha<.89$. The full-scale BADP had high reliability as well, Cronbach's $\alpha=.96$; please refer to Table 19 .

The subscales of the BADP (i.e., Fear, Anxiety, Depression, and Overall Negative Affectivity) for the combined sample also had high reliability with Cronbach's $\alpha$ of $.90<\alpha<$ 91. The full-scale BADP had high reliability as well, Cronbach's $\alpha=.97$, please refer to Table 20.

\section{Item Selection}

Final item selection of BADP involved examination and comparison of intra- and intercorrelation coefficients as well as PCA results. Specifically, items that did not cross-load onto multiple factors were examined in depth; please refer to Tables 16 and 17 for the factor loadings of the selected items. The CVR values based on the expert judges' ratings also were examined for each of the items. Based on the correlation coefficients, the CVR values, and the PCA results, the top four items from each subscale were selected. These items then were reviewed for ease of 
BRIEF ASSESSMENT OF DISTRESS AND PAIN

readability and the final items (i.e., one per subscale) of the BADP were selected; please refer to Table 21 .

\section{Discussion}

These data suggest the BADP is a good measure of negative affectivity related to pain. Items from the BADP were subjected to a stringent developmental process. Items were developed by a research group, evaluated by experts within the field of emotion and pain, tested in an undergraduate sample, and then applied to a heterogeneous sample of chronic pain patients.

Alpha coefficients for the BADP and its subscales indicated strong internal consistency. Intra-scale correlation coefficients revealed that subscales of the BADP were related. The high degree of relation among the subscales of the BADP was expected given the high degree of comorbidity of the constructs assessed by the BADP. There was still, however, some degree of distinction among the subscales of the BADP indicating that the BADP, was able to distinguish among the constructs to some extent.

Inter-scale correlation coefficients for the BADP indicated moderate to high degrees of convergent validity with the BDI-II, FPQ-III, and the PASS, all of which reflect similar constructs. In relation to divergent validity, correlation coefficients for the BADP indicated only a low association with the FQ-Ag. It was expected that the depression subscale and the overall negative affect subscale would be highly correlated given the degree of overlap of these particular constructs.

Of note, inter-correlation coefficients for the undergraduate sample were low as compared to the inter-correlation coefficients for the pain sample and the combined sample (i.e., pain and undergraduate sample) on all of the different subscales and scales in the battery of 
BRIEF ASSESSMENT OF DISTRESS AND PAIN

assessments. It is likely that this finding may reflect the undergraduate sample's limited experience with pain.

PCA results suggested a single component structure for the BADP which assesses overall negative affectivity in relation to the experience of pain. The PCA findings suggest that the BADP assesses a general emotional response to pain. The general nature of the responses may be related to different factors, depending on the sample. It is possible that the undergraduate sample has had limited experience with pain, which led to their responses being similar across scales.

Due to the pain sample's consistent and long-term experience with pain, they may have responded in such a way in which any negative emotions associated with pain are lumped together.

Despite the PCA indicating a single factor structure of the BADP, the goal in designing the BADP was to create a short assessment which could be administered in health-care settings. Even though the original plan was to create items which could distinguish among the constructs of fear, anxiety, depression, and overall negative affectivity, one overall item still could serve the desired purpose of early identification of individuals. Further, the use of a one item scale to identify clinically significant conditions would increase the ease of early assessment in healthcare settings and reduce the burden of scoring.

A limitation of the present study includes the small sample of chronic pain patients $(N=$ 45). The pain sample's data could not be investigated through a PCA in isolation, and had to be combined with undergraduate sample to provide a sufficient sample size for analysis. Specifically, variability in response patterns would have been more detectable if the two samples would have been kept separate. A larger heterogeneous chronic pain sample (i.e., $>100$ ) would have been more ideal for PCA to be conducted on the pain sample in isolation. Another 
BRIEF ASSESSMENT OF DISTRESS AND PAIN

limitation includes the use of different methods of assessment (i.e., SONA vs. paper and pencil format) across the two sample types. It would have been more ideal to choose one methodology across samples for consistency. The shorter battery presented to the pain sample was another limitation. The reduced assessment battery for the pain sample was beneficial in reducing burden, but limited the degree of comparison with the other assessments that were only included in the undergraduate assessment battery (i.e., ASI-3, TSK-11, FABQ, and the FQ-Ag). The ordering of the assessment batteries was different between samples. It would have been ideal to have administered the same assessments in the same sequence to both samples.

A strength of the present study was the multiple stages of analyses that were conducted to develop and analyze the BADP. Specifically, all items were developed based on construct definitions from the literature and were evaluated by members of a research group with experience in the area. The use of expert judges to evaluate each item and provide feedback increased the content validity of the items of the BADP. Another strength of the current study was the inclusion of the heterogeneous chronic pain sample, which allowed for analysis of the psychometric properties of the BADP with patients who are comparable to those whom the BADP was intended to assess.

There is a need for brief assessments in healthcare settings. Short assessments allow for ease of administration, scoring, and interpretation of clinical conditions and issues. Brief assessments can assist in early identification of affected individuals allowing for more comprehensive assessments and treatments. Although still early in the developmental phase, the BADP has displayed utility in identifying relations among negative emotional states and pain. The constructs assessed by the BADP (i.e., fear, anxiety, depression, and overall negative affectivity) are multi-dimensional in nature and are highly comorbid, leading to difficulty in 
BRIEF ASSESSMENT OF DISTRESS AND PAIN

designing an assessment that is capable of successfully making distinctions among the constructs. Nevertheless, the BADP, including its single item assessment, has great promise as a screening measure. Through further development and analysis, the BADP could address the need in the literature for a brief measure that assesses fear, anxiety, depression, and overall negative affectivity in relation to the experience of pain in health-based settings. 
BRIEF ASSESSMENT OF DISTRESS AND PAIN

References

Aiello-Laws, L., Reynolds, J., Deizer, N., Peterson, M., Ameringer, S., \& Bakitas, M. (2009).

Putting evidence into practice: What are the pharmacologic interventions for nociceptive and neuropathic cancer pain in adults?. Clinical Journal of Oncology Nursing, 13, 6, 649660. doi:10.1188/09.CJON.649-655.

American Academy of Orthopaedic Surgeons. Musculoskeletal conditions in the United States. Available at: http://orthoinfo.aaos.org/topic.cfm?topic=A00282. Accessed December 2, 2010.

American Psychiatric Association. (2013). Diagnostic and statistical manual of mental disorders (5th ed.). Washington, DC: Author.

Anastopoulos, A. D., \& Shelton, T. L. (2001). Assessment Procedures. In A. D. Anastopoulos \& T. L. Shelton (Eds.), Assessing Attention-Deficit/Hyperactivity Disorder (pp. 73-119). New York, NY: Kluwer Academic/Plenum Publishers.

Ang, D. C., Bair, M. J., Damush, T. M., Wu, J., Tu, W., \& Kroenke, K. (2010). Predictors of pain outcomes in patients with chronic musculoskeletal pain co-morbid with depression: Results from a randomized controlled trial. Pain Medicine, 11, 4, 482-491. doi:10.1111/j.1526-4637.2009.00759.x.

Asmundson, G. J. G., \& Katz, J. (2009). Understanding the co-occurrence of anxiety disorders and chronic pain: State-of-the-art. Depression and Anxiety, 26, 888-901. doi:10.1002/da.20600.

Asmundson, G. J., \& Norton, G. R. (1995). Anxiety sensitivity in patients with physically unexplained chronic back pain: A preliminary report. Behaviour Research and Therapy, $33,771-7$. 
BRIEF ASSESSMENT OF DISTRESS AND PAIN

Asmundson, G. J., Norton, P. J., \& Norton, G. R. (1999). Beyond pain: the role of fear and avoidance in chronicity. Clinical Psychology Review, 19, 1, 97-119. doi:10.1016/S02727358(98)00034-8.

Asmundson, G. J., Norton, P. J., \& Velaso, F. (1999). Anxiety sensitivity and fear of pain in patients with recurring headaches. Behaviour Research and Therapy, 37, 703-13.

Asmundson, G. J. G., \& Taylor, S. (1996). Role of anxiety sensitivity in pain-related fear and avoidance. Journal of Behavioral Medicine, 19, 577.

Bailey, K., Carleton, R. N., Vlaeyen, J., \& Asmundson, G. (2010). Treatments addressing pain-related fear and anxiety in patients with chronic musculoskeletal pain: A preliminary review. Cognitive Behaviour Therapy, 39, 1, 46-63. doi:10.1080/16506070902980711.

Bariselli, A. A., \& Bonetti, M. M. (2012). Non-invasive approaches to back pain in patients with somatization, 2nd review. International Journal of Ozone Therapy, 10, 104-107.

Beard, D., J., \& Aldington, D. (2011). Chronic pain after trauma. Trauma, 14, 1, 57-66. doi: $10.1177 / 1460408611412434$.

Beck, A. T., Steer, R.A., \& Brown G. K. (1996). Beck Depression Inventory-Second Edition Manual. San Antonio, TX: The Psychological Corporation.

Beesdo, K., Jacobi, F., Hoyer, J., Low, N. C. P., Höfler, M., \& Wittchen, H. U. (2010). Pain associated with specific anxiety and depressive disorders in a nationally representative population sample. Social Psychiatry and Psychiatric Epidemiology, 52, 1, 89-104. doi:10.1007/s00127-009-0045-1.

Beith, I. D., Kemp, A., Kenyon, J., Prout, M., \& Chestnut, T. J. (2011). Identifying neuropathic back and leg pain: A cross-sectional study. Pain, 152, 7, 1511-1516. doi: 10.1016/j.pain.2011.02.033. 
BRIEF ASSESSMENT OF DISTRESS AND PAIN

Bolles, R. C., \& Fanselow, M., S. (1980). A perceptual-defensive-recuperative model of fear and pain. Behavioral and Brain Sciences, 3, 291-323.

Bowling, A. (2005). Just one question: If one question works, why ask several?. Journal of Epidemiology and Community Health, 59, 342-345.

Bruehl, S., \& Chung, O. Y. (2004). Psychological interventions for acute pain. In T.

Hadjidtavropoulos \& K. D. Craig (Eds.). Pain: Psychological perspectives (pp. 245-269).

Mahwah, NJ: Lawrence Erlbaum Associates, Publishers.

Carleton, R. N., Abrams, M. P., Kachur, S. S., \& Asmundson, G. J. G. (2009). Waddell's symptoms as correlates of vulnerabilities associated with fear-anxiety-avoidance models of pain: Pain-related anxiety, catastrophic thinking, perceived disability, and treatment outcome. Journal of Occupational Rehabilitation, 19, 4, 364-374. doi:10.1007/s10926009-9191-2.

Carr, D. B., \& Goudas, L. C. (1999). Acute pain. Lancet, 353, 2051-2058.

Chapman, C. R., Nakamura, Y., \& Flores, L. Y. (1999). Chronic pain and consciousness: A constructivist perspective. In R. J. Gatchel \& D. C. Turk (Eds.). Psychosocial factors in pain: Critical perspectives (pp. 35-55). New York, NY: The Guilford Press.

Chronic Pain. (2008). In Encyclopedia of Counseling. Retrieved from: http://www.credoreference.com/entry/sagecouns/chronic_pain.

Clark, L. A., \& Watson, D. (1995). Constructing validity: Basic issues in objective scale development. Psychological Assessment, 7, 3, 309-19.

Cleeland, C., S. (1986). Behavioral control of symptoms how to treat a construct. Journal of Pain and Symptom Management, 1, 3, 161-162.

Costello, A. B., \& Osborne, J. W. (2005). Best factors in exploratory factor analysis: Four 
BRIEF ASSESSMENT OF DISTRESS AND PAIN

recommendations for getting the most from your analysis. Practical Assessment, Research \& Evaluation, 10, 7, 1-9.

Craske, M. G. (2003). Origins of phobias and anxiety disorders: Why more women than men?. Burlington: Elsevier

Dehghani, M., Sharpe, L., \& Nicholas, M. K. (2010). Structural evaluation of the contemporary psychological models of chronic pain: Does fear of pain work for all? Cognitive Behaviour Therapy, 39, 3, 214-224. doi: 10.1080/16506070903390134.

De Peuter, S., de Jong, J., Crombez, G., \& Vlaeyen, J. W. S. (2009). The nature and treatment of pain-related fear in chronic musculoskeletal pain. Journal of Cognitive Psychotherapy, 23, 1, 85-103. doi: 10.1891/0889-8391.23.1.85.

DeVeaugh-Geiss, A. M., West, S. L., Miller, W. C., Sleath, B., Gaynes, B. N., \& Kroenke, K. (2010). The adverse effects of comorbid pain on depression outcomes in primary care patients: Results from the artist trial. Pain Medicine, 11, 5, 732-741. doi: 10.1111/j.15264637.2010.00830.x.

DeVellis, R. F. (2003). Scale development: Theory and applications. (Second ed., Vol. 26, pp. 1-171). Thousand Oaks, California: Sage Publications, Inc.

Eken, C., Otay, C., Bacanli, A., Gulen, B., Cete, Y., Koparan, C., \& Ugras, S. S. (2010). Anxiety and depressive disorders in patients presenting with chest pain to the emergency department: A comparison between cardiac and non-cardiac origin. Journal of Emergency Medicine, 39, 144-150.

Faragher, E. B., Cooper, C. L., \& Cartwright, S. (2004). A shortened stress evaluation tool (ASSET). Stress and Health, 20, 189-201. 
BRIEF ASSESSMENT OF DISTRESS AND PAIN

Field, A. (2009). Discovering Statistics Using SPSS. (3 ${ }^{\text {rd }}$ edition). Los Angeles, CA: SAGE Publications Ltd.

Fishbain, D. A., Bruns, D., Disorbio, J. M., \& Lewis, J. E. (2009a). Risk for five forms of suicidality in acute pain patients and chronic pain patients vs pain-free community controls. Pain Medicine, 10, 6, 1095-1105. doi:10.1111/j.1526-4637.2009.00682.x.

Fishbain, D. A., Lewis, J. E., Gao, J., Cole, B., \& Steele Rosomoff, R. R. (2009b). Is chronic pain associated with somatization/hypochondriasis? An evidence-based structured review. Pain Practice, 9, 449-467. doi:10.1111/j.1533-2500.2009.00309.x.

Furr, R. M., \& Bacharach, V. R. (2008). Psychometrics: An introduction. Los Angeles: Sage Publications.

Gallagher, R. M. (1999). The medical clinics of North America: Chronic pain. W. B. Saunders Company, Philadelphia, PA.

Gatchel, R. J. (1999). Perspectives on pain: A historical overview. In R. J. Gatchel \& D. C. Turk (Eds.). Psychosocial factors in pain: Critical perspectives (pp. 3-17). New York, NY: The Guilford Press.

Gatchel, R. J., \& Dersch, J. (2002). Psychological disorders and chronic pain: Are there causeand-effect relationships?. In D. C. Turk \& R. J. Gatchel (Eds.). Psychological approaches to pain management: A practioner's handbook (pp. 30-51). New York, NY: The Guilford Press.

Gilliam, W., Matsuura, J., Wolff, B., Burns, J. W., Quartana, P., \& Nappi, C. (2010). Interactive effects of catastrophizing and suppression on responses to acute pain: A test of an appraisal 3 emotion regulation model. Journal of Behavioral Medicine, 33, 3, 191 199. doi:10.1007/s10865-009-9245-0. 
BRIEF ASSESSMENT OF DISTRESS AND PAIN

Glenton, C. (2003). Chronic back pain sufferers - striving for the sick role. Social Science \& Medicine, 57, 2243. doi:10.1016/S0277-9536(03)00130-8.

Harris, R. E. (2011). Central pain states: A shift in thinking about chronic pain. Journal of Family Practice, 60, 9.

Houben, R., Leeuw, M., Vlaeyen, J., Goubert, L., \& Picavet, H. (2005). Fear of movement/injury in the general population: Factor structure and psychometric properties of an adapted version of the Tampa Scale for Kinesiophobia. Journal of Behavioral Medicine, 28, 5, 415-424. doi:10.1007/s10865-005-9011-x.

International association for the study of pain: Iasp taxonomy. (2011). Retrieved from: http://www.iasppain.org/AM/Template.cfm?Section=Pain_Defi...isplay.cfm\&ContentID $=1728$.

Karoly, P., Okun, M., A., Ruehlman, L., S., \& Pugliese, J., A. (2008). The impact of goal cognition and pain severity on disability and depression in adults with chronic pain: An examination of direct effects and mediated effects via pain-induced fear. Cogntive Therapy Research, 32, 418-433. doi:10.1007/s10608-007-9136-z.

Keene, D. D., Rea, W. E., \& Aldington, D. (2011). Acute pain management in trauma. Trauma, 13, 3, 167-179. doi: 10.1177/1460408611400813.

Keogh, E., \& Mansoor, L. (2001). Investigating the effects of anxiety sensitivity and coping on the perception of cold pressor pain in healthy women. European Journal of Pain, 5, 1122. doi:10.1053/eujp.2000.0210.

Kincaid, J.P., Fishburne, R.P. Jr., Rogers, R.L., \& Chissom, B. S. (1975). Derivation of new 
BRIEF ASSESSMENT OF DISTRESS AND PAIN

readability formulas (Automated Readability Index and Flesch Reading Ease Formula) for navy enlisted personnel. Research Branch Report 8-75, Millington, TN: Naval Technical Training, U. S. Naval Air Station, Memphis, TN.

Kleinknecht, R. A., Klepac, R. K., \& Alexander, L. D. (1973). Origins and characteristics of fear of dentistry. Journal of the American Dental Association (1939), 86, 4, 842-8.

Krebs, E. E., Lorenz, K. A., Bair, M. J., Damush, T. M., Sutherland, J. M., Sutherland, J. M., Asch, S. M., \& Kroenke, K. (2009). Development and initial validation of the PEG, a three-item scale assessing pain intensity and interference. Journal of General Internal Medicine, 24, 6, 733-738. doi:10.1007/s11606-009-0981-1.

Lawshe, C. H. (1975). A quantitative approach to content validity. Personnel Psychology, 28, 563-575.

Leeuw, M., Goossens, M., Linton, S., Crombez, G., Boersma, K., \& Vlaeyen, J. (2007). The fear-avoidance model of musculoskeletal pain: Current state of scientific evidence. Journal of Behavioral Medicine, 30, 1, 77-94. doi:10.1007/s10865-006-9085-0.

Lerman, S. F., Shahar, G., \& Rudich, Z. (2010). Distinguishing affective and somatic dimensions of pain and depression: A confirmatory factor analytic study. Journal of Clinical Psychology, 66, 4, 456-465. doi: 10.1002/jclp.20674.

Lingard, H.C. and Rowlinson, S. (2005) Sample size in factor analysis: Why size matters: retrieved from: http://rec.hku.hk/steve/MSc/factoranalysisnoteforstudentresourcepage.pdf. 1-6.

Linton, S. J., \& Shaw, W. S. (2011). Impact of psychological factors in the experience of pain. Physical Therapy, 91, 5, 700-711. doi: 10.2522/ptj.20100330.

Lipowski, Z. J. (1988). Somatization: the concept and its clinical application. American 
BRIEF ASSESSMENT OF DISTRESS AND PAIN

Journal of Psychiatry, 145, 1358-68.

Lumley, M. A., Cohen, J. L., Borszcz, G. S., Cano, A., Radcliffe, A. M., Porter, L. S., Schubiner, H., \& Keefe, F. J. (2011). Pain and emotion: A biopsychosocial review of recent research. Journal of Clinical Psychology, 67, 9, 942-968. doi:10.1002/jclp.20816.

Marks, I. M., \& Mathews, A., (1979). Brief standard self-rating for phobic patients. Behaviour Research and Therapy, 17, 263-267.

McCracken, L. M., Zayfert, C., \& Gross, R. T. (1992). The Pain Anxiety Symptoms Scale: Development and validation of a scale to measure fear of pain. Pain, 50, 1, 67-73. doi:10.1016/0304-3959(92)90113-P.

McNeil, D.W., \& Rainwater, A. J. (1998). Development of the Fear of Pain QuestionnaireIII. Journal of Behavioral Medicine, 21, 4, 389. doi:10.1023/A:1018782831217.

McNeil, D. W., \& van Wijk, A. (2005). Understanding and assessing fear of dental pain. "Lunch and Learn" session presented at the meeting of the American/International Association for Dental Research, Baltimore, MD

Melzack, R., \& Wall, P.D. (1965). Pain mechanisms: A new theory. Science, 150, 971-79.

Mitchell, G. A., \& Harrison, D. W. (2010). Neuropsychological effects of hostility and pain on emotion perception. Journal of Clinical and Experimental Neuropsychology, 32, 2, 174-189. doi:10.1080/13803390902889614.

Mok, L. C., \& Lee, I. F. K. (2008). Anxiety, depression and pain intensity in patients with low back pain who are admitted to acute care hospitals. Journal of Clinical Nursing, 17, 11, 1471-1480. doi:10.1111/j.1365-2702.2007.02037.x.

Norton, P. J., \& Asmundson, G. J. (2004). Anxiety sensitivity, fear, and avoidance behavior in headache pain. Pain Amsterdam, 111, 218-223. doi: 10.1016/j.pain.2004.06.018. 
BRIEF ASSESSMENT OF DISTRESS AND PAIN

Ohayon, M. M. \& Schatzberg, A. F. (2003). Using chronic pain to predict depressive morbidity in the general population, Archives of General Psychiatry, 60, 39-47.

Ong, L., Cribbie, R., Harris, L., Dorian, P., Newman, D., Mangat, I., Nolan, R, Irvine, J. (2006). Psychological correlates of quality of life in atrial fibrillation. Quality of Life Research, 15, 1323-1333. doi: 10.1007/s11136-006-0029-5.

Pain, chronic. (2009). In Mosby's Dictionary of Medicine, Nursing, \& Health Professions. Retrieved from: http://www.credoreference.com/entry/ehsmosbymed/pain_chronic.

Polatin, P. B., \& Gajraj, N. M. (2002). Psychological disorders and chronic pain: Are there cause-and-effect relationships?. In D. C. Turk \& R. J. Gatchel (Eds.). Psychological approaches to pain management: A practioner's handbook (pp. 276-298). New York, NY: The Guilford Press.

Poleshuck, E. L., Gamble, S. A., Cort, N., Cerrito, B., Rosario-McCabe, L. A., Hoffman-King, D., \& Giles, D. E. (2010). Interpersonal psychotherapy for co-occurring depression and chronic pain. Professional Psychology: Research and Practice, 41, 4, 312-318. doi: $10.1037 / \mathrm{n} 0019924$.

Quartana, P. J., Campbell, C. M., \& Edwards, R. R. (2009). Pain catastrophizing: A critical review. Expert Review of Neurotherapeutics, 9, 745-58. doi: 10.1586/ERN.09.34.

Quartana, P. J., Bounds, S., Yoon, K. L., Goodin, B. R., \& Burns, J. W. (2010). Anger suppression predicts pain, emotional, and cardiovascular responses to the cold pressor. Annals of Behavioral Medicine : a Publication of the Society of Behavioral Medicine, 39, 3, 211-21. doi: 10.1007/s12160-010-9182-8.

Reneman, M., Schiphorts, P. H., Kleen, M., Geertzen, J., \& Dijkstra, P. (2007). Are pain intensity and pain related fear related to functional capacity evaluation performances of 
BRIEF ASSESSMENT OF DISTRESS AND PAIN

patients with chronic low back pain?. Journal of Occupational Rehabilitation, 17, 2, 247258. doi: 10.1007/s10926-007-9078-z.

Robinson, J. P. (2007). Chronic pain. Physical Medicine and Rehabilitation Clinics of North America, 18, 761-783.

Rode, S., Salkovskis, P., Dowd, H., \& Hanna, M. (2006). Health anxiety levels in chronic pain clinic attenders. Journal Of Psychosomatic Research, 60, 155-161. doi:10.1016/j.jpsychores.2005.07.005.

Roy, M., Piche, M., Chen, J. I., Peretz, I., \& Rainville, P. (2010). Cerebral and spinal modulation of pain by emotions. Proceedings of the National Academy of Sciences of the United States of America, 106, 49, 20900-20905. doi: 10.1073/pnas.0904706106.

Ruscheweyh, R., Wilder-Smith, O., Drdla, R., Liu, X. G., \& Sandkühler, J. (2011). Longterm potentiation in spinal nociceptive pathways as a novel target for pain therapy. Molecular Pain, 7.doi: 10.1186/1744-8069-7-20.

Schattner, E., \& Shahar, G. (2011). Role of pain personification in pain-related depression: An object relations perspective. Psychiatry, 74, 1, 14-20. doi: 10.1521/psyc.2011.74.1.14.

Sinatra, R. (2010). Causes and consequences of inadequate management of acute pain. Pain Medicine, 11, 1859-1871. doi: 10.1111/j.1526-4637.2010.00983.x.

Skevington, S. M. (1998). Investigating the relationship between pain and discomfort and quality of life, using the WHOQOL. Pain Amsterdam, 76, 395-406. doi: 10.1016/S03043959(98)00072-4.

Sprinkle, S. D., Lurie, D., Insko, S. L., Atkinson, G., Jones, G. L., Logan, A. R., \& Bissada, N. N. (2002). Criterion validity, severity cut scores, and test-retest reliability of the Beck 
BRIEF ASSESSMENT OF DISTRESS AND PAIN

Depression Inventory-II in a university counseling center sample. Journal of Counseling Psychology, 49, 381-385. doi: 10.1037/0022-0167.49.3.381.

Stewart, S. H., \& Asmundson, G. J. G. (2006). Anxiety sensitivity and its impact on pain experiences and conditions: A state of the art. Cognitive Behaviour Therapy, 35, 185-188. doi: $10.1080 / 16506070601090457$.

Storch, E. A., Roberti, J. W., \& Roth, D. A. (2004). Factor structure, concurrent validity, and internal consistency of the Beck Depression Inventory — second edition in a sample of college students. Depression and Anxiety, 19(3), 187-189. doi: 10.1002/da.20002.

Taylor S., Zvolensky, M. J., Cox, B. J., Deacon, B., Heimberg, R. G., Ledley, D. R., Abramowitz, J. S., \& Cardenas, S. J. (2007). Robust dimensions of anxiety sensitivity: Development and initial validation of the Anxiety Sensitivity Index-3. Psychological Assessment, 19, 176-188.

The American Academy of Pain Medicine. (n. d.). AAPM facts and figures on pain. Retrieved from: http://www.painmed.org/patient/facts.html\#refer.

Turk, D. C. (2006). Pain hurts: Individuals, significant others, and society! APS Bulletin, 16, 3.

Turk, D. C., \& Flor, H. (1999). Chronic pain: A behavioral perspective. In R. J. Gatchel \& D. C. Turk (Eds.). Psychosocial factors in pain: Critical perspectives (pp. 18-34). New York, NY: The Guilford Press.

Uman, L., Stewart, S., Watt, M., \& Johnston, A. (2006). Differences in high and low anxiety sensitive women's responses to a laboratory-based cold pressor task. Cognitive Behaviour Therapy, 35, 189-197. doi: 10.1080/16506070600898512.

Uysal, A., \& Lu, Q. (2011). Is self-concealment associated with acute and chronic pain?. Health Psychology, 30, 5, 606-614. doi: 10.1037/a0024287. 
BRIEF ASSESSMENT OF DISTRESS AND PAIN

Vadalouca, A., Moka, E., Chatzidimitriou, A., Siafaka, I., Sikioti, P., \& Argyra, E. (2009).

Original article: A randomized, double-blind, placebo-controlled study of preemptively administered intravenous parecoxib: Effect on anxiety levels and procedural pain during epidural catheter placement for surgical operations or for chronic pain therapy. Pain Practice, 9, 3, 181-194. doi: 10.1111/j.1533-2500.2009.00271.x.

Vowles, K. E., McNeil, D. W., Sorrell, J. T., \& Lawrence, S. M. (2006). Fear and pain: Investigating the interaction between aversive states. Journal of Abnormal Psychology, 115, 4, 821-833. doi: 10.1037/0021-843X.115.4821.

Waddell, G., Newton, M., Henderson, I., Somerville, D., \& Main, C. J. (1993). A fear-avoidance beliefs questionnaire (FABQ) and the role of fear-avoidance beliefs in chronic low back pain and disability. Pain, 52, 2, 157-168. doi: 10.1016/0304-3959(93)90127-B.

Ware, J. E., Kosinski, M., Keller, S.D. (1996). A 12-item short-form health survey construction of scales and preliminary tests of reliability and validity. Med Care, 34, 3, 220-233.

Watt, M., Stewart, S., Lefaivre, M. J., \& Uman, L. (2006). A brief cognitive-behavioral approach to reducing anxiety sensitivity decreases pain-related anxiety. Cognitive Behaviour Therapy, 35, 248-256. doi: 10.1080/16506070600898553.

White, K. S., Craft, J. M., \& Gervino, E. V. (2010). Anxiety and hypervigilance to cardiopulmonary sensations in non-cardiac chest pain patients with and without psychiatric disorders. Behaviour Research and Therapy, 48, 394-401. doi: 10.1016/j.brat.2010.01.001.

Williams, D. A. (1999). Chronic pain and consciousness: A constructivist perspective. In R. J. Gatchel \& D. C. Turk (Eds.). Psychosocial factors in pain: Critical perspectives (pp. 151-163). New York, NY: The Guilford Press. 
BRIEF ASSESSMENT OF DISTRESS AND PAIN

Winteridge, W. (2009). Chronic pain. Nursing Standard, 23, 48-56.

Woby, S. R., Roach, N. K., Urmston, M., \& Watson, P. J. (2005). Psychometric properties of the TSK-11: A shortened version of the tampa scale for kinesiophobia. Pain, 117, 1-2. doi: 10.1016/j.pain.2005.05.029.

World Bank (2011). Gross domestic product 2010. Retrieved from: http://siteresources.worldbank.org/DATASTATISTICS/Resources/GDP.pdf.

Zeller, J. L., Burke, A. E., \& Glass, R. M. (2008). Acute pain treatment. Journal of the American Medical Association, 299. 


\section{BRIEF ASSESSMENT OF DISTRESS AND PAIN}

Table 1.

Flesch-Kincaid Readability Tests

\begin{tabular}{|c|c|c|c|c|c|c|c|c|c|c|}
\hline $\begin{array}{l}\text { BADP Item } \\
\text { Number }\end{array}$ & $\begin{array}{l}\text { 1. Thinking } \\
\text { ahead about } \\
\text { something } \\
\text { painful, I get } \\
\text { really worried }\end{array}$ & $\begin{array}{l}\text { 2. All in all, I get } \\
\text { emotionally } \\
\text { upset about } \\
\text { pain. }\end{array}$ & $\begin{array}{l}\text { 3. I feel } \\
\text { hopeless } \\
\text { about } \\
\text { situations in } \\
\text { which I am } \\
\text { not able to } \\
\text { control or } \\
\text { reduce pain. }\end{array}$ & $\begin{array}{l}\text { 4. I fear } \\
\text { situations } \\
\text { that are } \\
\text { physically } \\
\text { painful. }\end{array}$ & $\begin{array}{l}\text { 5. Just before I } \\
\text { experience } \\
\text { something } \\
\text { painful, I get } \\
\text { really uptight. }\end{array}$ & $\begin{array}{l}6 . \text { The } \\
\text { fact that I } \\
\text { might feel } \\
\text { pain } \\
\text { causes } \\
\text { me to } \\
\text { feel sad. }\end{array}$ & $\begin{array}{l}\text { 7. Pain } \\
\text { causes me } \\
\text { to have } \\
\text { strong } \\
\text { negative } \\
\text { feelings }\end{array}$ & $\begin{array}{l}\text { 8. It is } \\
\text { difficult to } \\
\text { not be } \\
\text { afraid of } \\
\text { pain. }\end{array}$ & $\begin{array}{l}\text { 9. I worry } \\
\text { about } \\
\text { feeling } \\
\text { pain }\end{array}$ & $\begin{array}{l}\text { 10. I feel sad } \\
\text { about the } \\
\text { thought of } \\
\text { feeling pain. }\end{array}$ \\
\hline \multicolumn{11}{|l|}{ Grade } \\
\hline Level & 10.2 & 7.5 & 8.3 & 9 & 9.5 & 1.8 & 5.2 & 3.6 & 5.2 & 2.3 \\
\hline $\begin{array}{c}\text { Readability } \\
\text { Ease }\end{array}$ & 37.9 & 56.7 & 63.6 & 42.6 & 44.4 & 100 & 71.8 & 84.9 & 66.4 & 94.3 \\
\hline
\end{tabular}

Note. The 20-item version of the BADP administered to both samples. The readability ease test is based on the mathematical formula that assesses average sentence length and the average number of syllables per word. Easier to read sentences have higher readability ease scores. Scores of 90-100 are at a $5^{\text {th }}$ grade level. Scores of 60-70 are at an 8-9 ${ }^{\text {th }}$ grade level. Scores of 0-30 are at a college graduate level.

*MyByline Media. (2013). The Flesch Reading Ease Readability Formula. Readability Formulas: Free readability tools to check Reading Levels, Reading Assessment, and Reading Grade Levels. Retrieved from: http://www.readabilityformulas.com/flesch-reading-ease-readability-formula.php. 


\section{BRIEF ASSESSMENT OF DISTRESS AND PAIN}

Table 2.

Flesch-Kincaid Readability Tests continued

\begin{tabular}{|c|c|c|c|c|c|c|c|c|c|c|}
\hline $\begin{array}{l}\text { BADP Item } \\
\text { Number }\end{array}$ & $\begin{array}{l}\text { 11. The fact } \\
\text { that I could } \\
\text { feel pain in } \\
\text { the } \\
\text { future } \\
\text { worries me a } \\
\text { lot. }\end{array}$ & $\begin{array}{l}\text { 12. I am } \\
\text { emotionally } \\
\text { upset when I } \\
\text { experience } \\
\text { pain }\end{array}$ & $\begin{array}{l}\text { 13. I am } \\
\text { scared of } \\
\text { feeling pain. }\end{array}$ & $\begin{array}{l}\text { 14. When I } \\
\text { am in pain, I } \\
\text { feel } \\
\text { hopeless. }\end{array}$ & $\begin{array}{l}\text { 15. I feel really } \\
\text { nervous when } \\
\text { I think about } \\
\text { being in pain. }\end{array}$ & $\begin{array}{l}\text { 16. I feel } \\
\text { a sudden } \\
\text { sense of } \\
\text { fear I am } \\
\text { about to } \\
\text { feel pain }\end{array}$ & $\begin{array}{l}\text { 17. Being } \\
\text { in pain } \\
\text { makes me } \\
\text { feel sad. }\end{array}$ & $\begin{array}{l}\text { 18. I am } \\
\text { really } \\
\text { troubled } \\
\text { when I } \\
\text { think about } \\
\text { my pain. }\end{array}$ & $\begin{array}{l}\text { 19. It is } \\
\text { hard to not } \\
\text { be worried } \\
\text { about my } \\
\text { pain. }\end{array}$ & $\begin{array}{l}\text { 20. All in all, } \\
\text { pain causes me } \\
\text { to feel } \\
\text { emotionally } \\
\text { distressed. }\end{array}$ \\
\hline \multicolumn{11}{|l|}{ Grade } \\
\hline Level & 3.3 & 9.6 & 0.5 & 2.2 & 3.7 & 3 & 0 & 3.6 & 2.4 & 7.1 \\
\hline $\begin{array}{c}\text { Readability } \\
\text { Ease }\end{array}$ & 95.9 & 40 & 100 & 92.9 & 87.9 & 96 & 100 & 86.7 & 95.1 & 61.3 \\
\hline
\end{tabular}

Note. The 20-item version of the BADP administered to both samples. The readability ease test is based on the mathematical formula that assesses average sentence length and the average number of syllables per word. Easier to read sentences have higher readability ease scores. Scores of 90-100 are at a $5^{\text {th }}$ grade level. Scores of 60-70 are at an 8-9 ${ }^{\text {th }}$ grade level. Scores of 0-30 are at a college graduate level.

*MyByline Media. (2013). The Flesch Reading Ease Readability Formula. Readability Formulas: Free readability tools to check Reading Levels, Reading Assessment, and Reading Grade Levels. Retrieved from: http://www.readabilityformulas.com/flesch-reading-ease-readability-formula.php. 
BRIEF ASSESSMENT OF DISTRESS AND PAIN

Table 3.

CVRs for the Fear Subscale

FEAR

1. I am scared of feeling pain.

2. I avoid painful situations at all costs because I feel afraid.

3. Feeling pain causes me to feel frightened.

4. I feel scared just before I have pain.

5. I am very afraid of situations in which I am not able to control pain.

6. When I think about being in pain, I feel scared.

7. Knowing that I am going to have pain is very scary to me.

8. I fear parts of life that are physically painful.

9. When I am in pain, I feel scared.

10. It is difficult to not be afraid of pain.

11. When I am about to experience pain, I become fearful.

CVR-Essential and

Maybe Essential

12. Just before I experience something painful, I get really uptight.

13. When I am just about to experience pain, fear overwhelms me.

14. When pain is about to begin, I feel afraid.

15. Fear comes over me when I know I am about to feel pain. 
BRIEF ASSESSMENT OF DISTRESS AND PAIN

Table 4.

CVR for the Anxiety Subscale

ANXIETY

CVR-Essential and Maybe

Essential

1. I worry about feeling pain.

1.0

2. I worry about situations that probably will involve pain.

1.0

3. I avoid painful situations at all costs because I am anxious.

4. I worry about painful situations.

5. I am nervous about pain.

6. The fact that I could feel pain in the future worries me a lot.

7. Knowing that I will likely experience pain makes me feel anxious.

8. I feel anxious when I think about being in pain.

9. It is hard to not be worried about pain.

10. When I think about being in pain, I feel anxious.

11. I feel nervous when I think about experiencing something painful.

12. I worry a lot about pain.

13. Thinking ahead about something painful, I get really worried.

14. My nerves get really bad when I think about being in pain.

15. When I think about pain, I feel anxious. 
BRIEF ASSESSMENT OF DISTRESS AND PAIN

Table 5.

CVR for the Depression Subscale

\section{DEPRESSION}

CVR-Essential and Maybe Essential

1. I feel down about experiencing pain.

2. The thought of experiencing pain causes me to feel depressed.

3. Thinking about pain causes me to feel depressed.

4. Experiencing pain causes me to feel hopeless.

5. I feel depressed about pain.

6. I feel hopeless about situations in which I am not able to control or reduce pain.

7. The fact that I might feel pain causes me to feel sad.

8. Knowing that I will likely feel pain makes me feel helpless.

9. I feel sad about the thought of feeling pain.

10. When I am in pain, I feel hopeless.

11. When I think about being in pain, I feel sad.

12. I get really sad when I know I am going to experience something painful.

13. Sadness comes over me when I am in pain.

14. Being in pain makes me feel sad.

15. When I am about to experience pain, I become depressed. 
BRIEF ASSESSMENT OF DISTRESS AND PAIN

Table 6.

CVR for the Overall Negative Affectivity Subscale

OVERALL NEGATIVE AFFECT

1. All things considered, I have lots of concerns about pain.

2. I am troubled by situations in which I probably will feel pain.

3. Thinking about pain causes me to feel upset.

4. All in all, I get emotionally upset about pain.

5. Pain causes me to have strong negative feelings.

6. The fact that I could feel pain bothers me a lot.

7. Knowing that I will likely feel pain makes me feel awful.

8. I am bothered by the thought of going through pain.

9. Painful situations are emotionally distressing to me.

10. All in all, pain causes me to feel emotionally distraught.

11. I am really troubled when I think about pain.

12. When I think about being in pain, I feel

distressed.

13. All things considered, I have lots of negative emotions about feeling pain.

14. I am emotionally upset when I experience pain.

15. All things considered, I have lots of negative feelings about experiencing pain.
.64 
BRIEF ASSESSMENT OF DISTRESS AND PAIN

Table 7.

Descriptive Statistics and Comparison of Scores across Samples on Assessment Scales

\begin{tabular}{|c|c|c|c|c|c|c|c|}
\hline \multirow[t]{2}{*}{$\begin{array}{c}\text { Undergraduate } \\
\text { Sample }\end{array}$} & \multicolumn{5}{|c|}{ Pain Sample } & \multirow[b]{2}{*}{$t$} & \multirow[b]{2}{*}{$p$} \\
\hline & Mean & SD & & Mean & SD & & \\
\hline \multicolumn{8}{|c|}{ BADP } \\
\hline BADP Fear & & & BADP Fear & & & & \\
\hline Subscale & 7.55 & 4.53 & Subscale & 8.22 & 6.50 & .49 & .63 \\
\hline BADP Anxiety & & & BADP Anxiety & & & & \\
\hline Subscale & 6.78 & 4.38 & Subscale & 7.87 & 6.06 & 1.52 & .13 \\
\hline BADP Depression & & & BADP Depression & & & & \\
\hline Subscale & 5.36 & 4.12 & Subscale & 7.91 & 6.11 & 4.14 & $<.001$ \\
\hline BADP ONA & & & BADP ONA & & & & \\
\hline Subscale & 6.09 & 4.57 & Subscale & 8.44 & 6.56 & 3.12 & $<.05$ \\
\hline BADP Total & 25.79 & 16.27 & BADP Total & 32.44 & 24.46 & 2.46 & $<.05$ \\
\hline \multicolumn{8}{|c|}{ BDI-II } \\
\hline BDI-II Total & 10.13 & 9.59 & BDI-II Total & 17.73 & 11.23 & 4.96 & $<.001$ \\
\hline \multicolumn{8}{|c|}{ FPQ-III } \\
\hline FPQ-III Minor Pain & & & FPQ-III Minor Pain & & & & \\
\hline Subscale & 10.23 & 5.65 & Subscale & 20.13 & 11.07 & 9.90 & $<.001$ \\
\hline FPQ-III Severe & & & FPQ-III Severe & & & & \\
\hline Pain Subscale & 24.67 & 7.69 & Pain Subscale & 29.33 & 12.37 & 3.52 & $<.001$ \\
\hline FPQ-III Medical & & & FPQ-III Medical & & & & \\
\hline Pain Subscale & 16.92 & 7.97 & Pain Subscale & 23.91 & 11.40 & 5.33 & $<.001$ \\
\hline FPQ-III Total & 51.73 & 17.53 & FPQ-III Total & 73.38 & 32.65 & 6.99 & $<.001$ \\
\hline \multicolumn{8}{|c|}{ PASS } \\
\hline PASS Fear & & & PASS Fear & & & & \\
\hline Subscale & 20.45 & 6.51 & Subscale & 21.60 & 10.12 & -.30 & .76 \\
\hline PASS Cognitive & & & PASS Cognitive & & & & \\
\hline Anxiety Subscale & 22.79 & 6.91 & Anxiety Subscale & 20.11 & 10.64 & 1.06 & .29 \\
\hline PASS & & & PASS & & & & \\
\hline Escape/Avoidance & & & Escape/Avoidance & & & & \\
\hline Subscale & 23.36 & 6.37 & Subscale & 24.02 & 11.13 & 3.10 & $<.05$ \\
\hline PASS & & & PASS & & & & \\
\hline Physiological & & & Physiological & & & & \\
\hline Anxiety Subscale & 19.84 & 8.70 & Anxiety Subscale & 26.64 & 9.68 & .44 & .66 \\
\hline PASS Total & 86.46 & 25.27 & PASS Total & 91.24 & 40.55 & 1.14 & .25 \\
\hline
\end{tabular}

*Note. Student's $t$-tests reported. 


\section{BRIEF ASSESSMENT OF DISTRESS AND PAIN}

Table 8 .

Intra-scale Correlation Coefficients for Fear items

\begin{tabular}{|c|c|c|c|c|c|c|c|c|c|c|c|c|c|c|c|}
\hline Item \# & $\begin{array}{c}\text { Fear } \\
\text { Subscale- } \\
\text { UG }\end{array}$ & $\begin{array}{c}\text { Fear } \\
\text { Subscale- } \\
\text { Pain }\end{array}$ & $\begin{array}{c}\text { Fear } \\
\text { Subscale- } \\
\text { Both }\end{array}$ & $\begin{array}{c}\text { Anxiety } \\
\text { Subscale- } \\
\text { UG }\end{array}$ & $\begin{array}{c}\text { Anxiety } \\
\text { Subscale- } \\
\text { Pain }\end{array}$ & $\begin{array}{l}\text { Anxiety } \\
\text { Subscale- } \\
\text { Both }\end{array}$ & $\begin{array}{c}\text { Depression } \\
\text { Subscale- } \\
\text { UG }\end{array}$ & $\begin{array}{c}\text { Depression } \\
\text { Subscale- } \\
\text { Pain }\end{array}$ & $\begin{array}{c}\text { Depression } \\
\text { Subscale- } \\
\text { Both }\end{array}$ & $\begin{array}{c}\text { ONA } \\
\text { Subscale- } \\
\text { UG }\end{array}$ & $\begin{array}{c}\text { ONA } \\
\text { Subscale- } \\
\text { Pain }\end{array}$ & $\begin{array}{c}\text { ONA } \\
\text { Subscale- } \\
\text { Both }\end{array}$ & $\begin{array}{c}\text { Total- } \\
\text { UG }\end{array}$ & $\begin{array}{l}\text { Total- } \\
\text { Pain }\end{array}$ & $\begin{array}{c}\text { Total } \\
\text { Scale- } \\
\text { Both }\end{array}$ \\
\hline 4 & .81 & .91 & .82 & .70 & .79 & .71 & .57 & .79 & .60 & .62 & .74 & .63 & .73 & .83 & .74 \\
\hline 5 & .81 & .92 & .81 & .73 & .81 & .74 & .72 & .80 & .75 & .65 & .76 & .68 & .79 & .85 & .80 \\
\hline 8 & .85 & .92 & .86 & .75 & .88 & .77 & .63 & .87 & .65 & .66 & .85 & .68 & .78 & .90 & .79 \\
\hline 13 & .87 & .92 & .87 & .75 & .91 & .76 & .64 & .89 & .65 & .66 & .82 & .67 & .79 & .91 & .79 \\
\hline 16 & .83 & .93 & .84 & .76 & .87 & .77 & .61 & .85 & .62 & .68 & .81 & .68 & .78 & .89 & .78 \\
\hline
\end{tabular}

Note. All correlations were significant at $p<.01 ; \mathrm{UG}=$ Undergraduate Sample; Pain $=$ Pain Sample; Both $=$ Combined Sample; ONA

$=$ Overall Negative Affect subscale 


\section{BRIEF ASSESSMENT OF DISTRESS AND PAIN}

Table 9.

Intra-scale Correlation Coefficients for Anxiety Items

\begin{tabular}{|c|c|c|c|c|c|c|c|c|c|c|c|c|c|c|c|}
\hline Item \# & $\begin{array}{c}\text { Fear } \\
\text { Subscale- } \\
\text { UG }\end{array}$ & $\begin{array}{c}\text { Fear } \\
\text { Subscale- } \\
\text { Pain }\end{array}$ & $\begin{array}{c}\text { Fear } \\
\text { Subscale- } \\
\text { Both }\end{array}$ & $\begin{array}{c}\text { Anxiety } \\
\text { Subscale- } \\
\text { UG }\end{array}$ & $\begin{array}{c}\text { Anxiety } \\
\text { Subscale- } \\
\text { Pain }\end{array}$ & $\begin{array}{c}\text { Anxiety } \\
\text { Subscale- } \\
\text { Both }\end{array}$ & $\begin{array}{c}\text { Depression } \\
\text { Subscale- } \\
\text { UG }\end{array}$ & $\begin{array}{c}\text { Depression } \\
\text { Subscale- } \\
\text { Pain }\end{array}$ & $\begin{array}{c}\text { Depression } \\
\text { Subscale- } \\
\text { Both }\end{array}$ & $\begin{array}{c}\text { ONA } \\
\text { Subscale- } \\
\text { UG }\end{array}$ & $\begin{array}{c}\text { ONA } \\
\text { Subscale- } \\
\text { Pain }\end{array}$ & $\begin{array}{c}\text { ONA } \\
\text { Subscale- } \\
\text { Both }\end{array}$ & $\begin{array}{c}\text { Total- } \\
\text { UG }\end{array}$ & $\begin{array}{c}\text { Total- } \\
\text { Pain }\end{array}$ & $\begin{array}{c}\text { Total } \\
\text { Scale- } \\
\text { Both }\end{array}$ \\
\hline 1 & .71 & .82 & .72 & .80 & .87 & .81 & .57 & .83 & .60 & .61 & .82 & .64 & .73 & .86 & .74 \\
\hline 9 & .77 & .92 & .80 & .82 & .93 & .84 & .69 & .92 & .73 & .68 & .88 & .71 & .80 & .94 & .83 \\
\hline 11 & .63 & .78 & .65 & .76 & .91 & .78 & .52 & .83 & .56 & .61 & .81 & .63 & .68 & .86 & .70 \\
\hline 15 & .79 & .88 & .80 & .88 & .96 & .89 & .65 & .88 & .68 & .68 & .88 & .71 & .81 & .93 & .83 \\
\hline 19 & .74 & .87 & .75 & .83 & .95 & .85 & .66 & .92 & .71 & .70 & .93 & .74 & .79 & .94 & .82 \\
\hline
\end{tabular}

Note. All correlations were significant at $p<.01 ; \mathrm{UG}=$ Undergraduate Sample; Pain $=$ Pain Sample; Both = Combined Sample; ONA

= Overall Negative Affect subscale 


\section{BRIEF ASSESSMENT OF DISTRESS AND PAIN}

Table 10.

Intra-scale Correlation Coefficients for Depression items

\begin{tabular}{|c|c|c|c|c|c|c|c|c|c|c|c|c|c|c|c|}
\hline Item \# & $\begin{array}{c}\text { Fear } \\
\text { Subscale- } \\
\text { UG }\end{array}$ & $\begin{array}{c}\text { Fear } \\
\text { Subscale- } \\
\text { Pain }\end{array}$ & $\begin{array}{c}\text { Fear } \\
\text { Subscale- } \\
\text { Both }\end{array}$ & $\begin{array}{c}\text { Anxiety } \\
\text { Subscale- } \\
\text { UG }\end{array}$ & $\begin{array}{c}\text { Anxiety } \\
\text { Subscale- } \\
\text { Pain }\end{array}$ & $\begin{array}{c}\text { Anxiety } \\
\text { Subscale- } \\
\text { Both }\end{array}$ & $\begin{array}{c}\text { Depression } \\
\text { Subscale- } \\
\text { UG }\end{array}$ & $\begin{array}{c}\text { Depression } \\
\text { Subscale- } \\
\text { Pain }\end{array}$ & $\begin{array}{c}\text { Depression } \\
\text { Subscale- } \\
\text { Both }\end{array}$ & $\begin{array}{c}\text { ONA } \\
\text { Subscale- } \\
\text { UG }\end{array}$ & $\begin{array}{c}\text { ONA } \\
\text { Subscale- } \\
\text { Pain }\end{array}$ & $\begin{array}{c}\text { ONA } \\
\text { Subscale- } \\
\text { Both }\end{array}$ & $\begin{array}{c}\text { Total- } \\
\text { UG }\end{array}$ & $\begin{array}{c}\text { Total- } \\
\text { Pain }\end{array}$ & $\begin{array}{c}\text { Total } \\
\text { Scale- } \\
\text { Both }\end{array}$ \\
\hline 3 & .60 & .81 & .63 & .55 & .86 & .60 & .75 & .92 & .78 & .62 & .87 & .67 & .68 & .85 & .72 \\
\hline 6 & .67 & .90 & .70 & .66 & .88 & .70 & .84 & .91 & .85 & .69 & .85 & .72 & .77 & .91 & .80 \\
\hline 10 & .69 & .88 & .71 & .70 & .90 & .73 & .86 & .94 & .88 & .71 & .87 & .75 & .80 & .93 & .82 \\
\hline 14 & .62 & .81 & .65 & .62 & .90 & .66 & .84 & .93 & .86 & .77 & .90 & .79 & .77 & .91 & .79 \\
\hline 17 & .56 & .82 & .59 & .55 & .85 & .60 & .81 & .93 & .84 & .69 & .88 & .73 & .70 & .90 & .74 \\
\hline
\end{tabular}

Note. All correlations were significant at $p<.01 ; \mathrm{UG}=$ Undergraduate Sample; Pain = Pain Sample; Both = Combined Sample; ONA $=$ Overall Negative Affect subscale 


\section{BRIEF ASSESSMENT OF DISTRESS AND PAIN}

Table 11.

Intra-scale Correlation Coefficients for Overall Negative Affect items

\begin{tabular}{|c|c|c|c|c|c|c|c|c|c|c|c|c|c|c|c|}
\hline Item \# & $\begin{array}{c}\text { Fear } \\
\text { Subscale- } \\
\text { UG }\end{array}$ & $\begin{array}{c}\text { Fear } \\
\text { Subscale- } \\
\text { Pain }\end{array}$ & $\begin{array}{c}\text { Fear } \\
\text { Subscale- } \\
\text { Both }\end{array}$ & $\begin{array}{c}\text { Anxiety } \\
\text { Subscale- } \\
\text { UG }\end{array}$ & $\begin{array}{c}\text { Anxiety } \\
\text { Subscale- } \\
\text { Pain }\end{array}$ & $\begin{array}{c}\text { Anxiety } \\
\text { Subscale- } \\
\text { Both }\end{array}$ & $\begin{array}{c}\text { Depression } \\
\text { Subscale- } \\
\text { UG }\end{array}$ & $\begin{array}{c}\text { Depression } \\
\text { Subscale- } \\
\text { Pain }\end{array}$ & $\begin{array}{c}\text { Depression } \\
\text { Subscale- } \\
\text { Both }\end{array}$ & $\begin{array}{c}\text { ONA } \\
\text { Subscale- } \\
\text { UG }\end{array}$ & $\begin{array}{c}\text { ONA } \\
\text { Subscale- } \\
\text { Pain }\end{array}$ & $\begin{array}{c}\text { ONA } \\
\text { Subscale- } \\
\text { Both }\end{array}$ & $\begin{array}{c}\text { Total- } \\
\text { UG }\end{array}$ & $\begin{array}{c}\text { Total- } \\
\text { Pain }\end{array}$ & $\begin{array}{l}\text { Total } \\
\text { Scale- } \\
\text { Both }\end{array}$ \\
\hline 2 & .66 & .82 & .68 & .67 & .87 & .70 & .72 & .88 & .75 & .84 & .93 & .86 & .78 & .90 & .80 \\
\hline 7 & .64 & .73 & .65 & .63 & .80 & .66 & .70 & .81 & . 72 & .80 & .89 & .82 & .75 & .83 & . 77 \\
\hline 12 & .61 & .83 & .65 & .63 & .87 & .67 & .69 & .87 & .72 & .86 & .92 & .87 & .76 & .90 & .78 \\
\hline 18 & .72 & .80 & .73 & .75 & .90 & .78 & .74 & .89 & .77 & .82 & .94 & .84 & .82 & .91 & .84 \\
\hline 20 & .68 & .83 & .70 & .71 & .89 & .73 & .74 & .92 & .77 & .90 & .93 & .90 & .82 & .92 & .83 \\
\hline
\end{tabular}

Note. All correlations were significant at $p<.01 ; \mathrm{UG}=$ Undergraduate Sample; Pain = Pain Sample; Both = Combined Sample; ONA

= Overall Negative Affect subscale 
BRIEF ASSESSMENT OF DISTRESS AND PAIN

Table 12.

Inter-Scale Correlation Coefficients for Fear Subscale

\begin{tabular}{cccccccccc} 
Fear Items & $\begin{array}{c}\text { BDI } \\
\text { Total- } \\
\text { UG }\end{array}$ & $\begin{array}{c}\text { BDI } \\
\text { Total- } \\
\text { Pain }\end{array}$ & $\begin{array}{c}\text { BDI } \\
\text { Total- } \\
\text { Both }\end{array}$ & $\begin{array}{c}\text { FPQ } \\
\text { Total- } \\
\text { UG }\end{array}$ & $\begin{array}{c}\text { FPQ } \\
\text { Total- } \\
\text { Pain }\end{array}$ & $\begin{array}{c}\text { FPQ } \\
\text { Total- } \\
\text { Both }\end{array}$ & $\begin{array}{c}\text { PASS } \\
\text { Total- } \\
\text { UG }\end{array}$ & $\begin{array}{c}\text { PASS } \\
\text { Total- } \\
\text { Pain }\end{array}$ & $\begin{array}{c}\text { PASS } \\
\text { Total- } \\
\text { Both }\end{array}$ \\
\hline 4 & .12 & .53 & .17 & .45 & .62 & .45 & .57 & .72 & .59 \\
5 & .20 & .51 & .28 & .38 & .61 & .46 & .49 & .77 & .54 \\
8 & .19 & .52 & .24 & .40 & .67 & .43 & .56 & .72 & .58 \\
13 & .20 & .59 & .23 & .46 & .74 & .46 & .55 & .78 & .57 \\
16 & .24 & .58 & .26 & .44 & .71 & .44 & .60 & .79 & .62 \\
$\quad \begin{array}{l}\text { Fear } \\
\text { Subscale }\end{array}$ & .23 & .59 & .28 & .51 & .73 & .53 & .66 & .82 & .69 \\
\hline
\end{tabular}

Note. All correlations were significant at $p<.01 ; \mathrm{UG}=$ Undergraduate Sample; Pain $=$ Pain Sample; Both $=$ Combined Sample 


\section{BRIEF ASSESSMENT OF DISTRESS AND PAIN}

Table 13.

Inter-Scale Correlation Coefficients for Anxiety Subscale

\begin{tabular}{cccccccccc}
$\begin{array}{c}\text { Anxiety } \\
\text { Items }\end{array}$ & $\begin{array}{c}\text { BDI } \\
\text { Total- } \\
\text { UG }\end{array}$ & $\begin{array}{c}\text { BDI } \\
\text { Total- } \\
\text { Pain }\end{array}$ & $\begin{array}{c}\text { BDI } \\
\text { Total- } \\
\text { Both }\end{array}$ & $\begin{array}{c}\text { FPQ } \\
\text { Total- } \\
\text { UG }\end{array}$ & $\begin{array}{c}\text { FPQ } \\
\text { Total- } \\
\text { Pain }\end{array}$ & $\begin{array}{c}\text { FPQ } \\
\text { Total- } \\
\text { Both }\end{array}$ & $\begin{array}{c}\text { PASS } \\
\text { Total- } \\
\text { UG }\end{array}$ & $\begin{array}{c}\text { PASS } \\
\text { Total- } \\
\text { Pain }\end{array}$ & $\begin{array}{c}\text { PASS } \\
\text { Total- } \\
\text { Both }\end{array}$ \\
\hline 1 & .18 & .65 & .23 & .40 & .59 & .41 & .53 & .73 & .56 \\
9 & .22 & .59 & .28 & .38 & .70 & .44 & .58 & .79 & .61 \\
11 & .18 & .61 & .23 & .40 & .66 & .43 & .48 & .75 & .52 \\
15 & .18 & .60 & .25 & .45 & .63 & .48 & .57 & .75 & .60 \\
19 & .25 & .66 & .33 & .37 & .62 & .44 & .57 & .77 & .60 \\
Anxiety & & & & & & & & & \\
Subscale & .25 & .67 & .32 & .49 & .69 & .52 & .67 & .82 & .69 \\
\hline
\end{tabular}

Note. All correlations were significant at $p<.01 ; \mathrm{UG}=$ Undergraduate Sample; Pain $=$ Pain Sample; Both $=$ Combined Sample 


\section{BRIEF ASSESSMENT OF DISTRESS AND PAIN}

Table 14.

Inter-Scale Correlation Coefficients for Depression Subscale

\begin{tabular}{cccccccccc}
$\begin{array}{c}\text { Depression } \\
\text { Subscale } \\
\text { Items }\end{array}$ & $\begin{array}{c}\text { BDI } \\
\text { Total- } \\
\text { UG }\end{array}$ & $\begin{array}{c}\text { BDI } \\
\text { Total- } \\
\text { Pain }\end{array}$ & $\begin{array}{c}\text { BDI } \\
\text { Total- } \\
\text { Both }\end{array}$ & $\begin{array}{c}\text { FPQ } \\
\text { Total- } \\
\text { UG }\end{array}$ & $\begin{array}{c}\text { FPQ } \\
\text { Total- } \\
\text { Pain }\end{array}$ & $\begin{array}{c}\text { FPQ } \\
\text { Total- } \\
\text { Both }\end{array}$ & $\begin{array}{c}\text { PASS } \\
\text { Total- } \\
\text { UG }\end{array}$ & $\begin{array}{c}\text { PASS } \\
\text { Total- } \\
\text { Pain }\end{array}$ & $\begin{array}{c}\text { PASS } \\
\text { Total- } \\
\text { Both }\end{array}$ \\
\hline 3 & .32 & .62 & .37 & .39 & .53 & .42 & .60 & .77 & .63 \\
6 & .27 & .57 & .34 & .31 & .67 & .42 & .53 & .78 & .58 \\
10 & .23 & .57 & .32 & .38 & .67 & .48 & .55 & .79 & .58 \\
14 & .34 & .68 & .40 & .32 & .67 & .40 & .62 & .80 & .65 \\
17 & .25 & .63 & .34 & .32 & .64 & .43 & .50 & .80 & .55 \\
$\begin{array}{c}\text { Depression } \\
\text { Subscale }\end{array}$ & .35 & .66 & .42 & .42 & .69 & .51 & .68 & .85 & .71 \\
\hline
\end{tabular}

Note. All correlations were significant at $p<.01 ; \mathrm{UG}=$ Undergraduate Sample; Pain $=$ Pain Sample; Both $=$ Combined Sample 
BRIEF ASSESSMENT OF DISTRESS AND PAIN

Table 15.

Inter-Scale Correlation Coefficients for Overall Negative Affect Subscale

\begin{tabular}{|c|c|c|c|c|c|c|c|c|c|}
\hline ONA Items & $\begin{array}{c}\text { BDI } \\
\text { Total- } \\
\text { UG } \\
\end{array}$ & $\begin{array}{c}\text { BDI } \\
\text { Total- } \\
\text { Pain }\end{array}$ & $\begin{array}{c}\text { BDI } \\
\text { Total-B }\end{array}$ & $\begin{array}{c}\text { FPQ } \\
\text { Total- } \\
\text { UG } \\
\end{array}$ & $\begin{array}{c}\text { FPQ } \\
\text { Total- } \\
\text { Pain }\end{array}$ & $\begin{array}{c}\text { FPQ } \\
\text { Total-B }\end{array}$ & $\begin{array}{c}\text { PASS } \\
\text { Total- } \\
\text { UG } \\
\end{array}$ & $\begin{array}{c}\text { PASS } \\
\text { Total- } \\
\text { Pain }\end{array}$ & $\begin{array}{c}\text { PASS } \\
\text { Total-B }\end{array}$ \\
\hline 2 & .31 & .69 & .38 & .38 & .60 & .43 & .64 & .82 & .66 \\
\hline 7 & .29 & .69 & .36 & .30 & .46 & .36 & .59 & .69 & .61 \\
\hline 12 & .26 & .69 & .33 & .35 & .63 & .41 & .61 & .77 & .63 \\
\hline 18 & .25 & .69 & .34 & .35 & .52 & .40 & .59 & .77 & .62 \\
\hline 20 & .29 & .66 & .36 & .36 & .62 & .42 & .61 & .85 & .64 \\
\hline $\begin{array}{c}\text { ONA } \\
\text { Subscale }\end{array}$ & .33 & .74 & .41 & .41 & .61 & .47 & .71 & .84 & .74 \\
\hline
\end{tabular}

Note. All correlations were significant at $p<.01 ; \mathrm{ONA}=$ Overall Negative Affect; $\mathrm{UG}=$ Undergraduate Sample; Pain $=$ Pain Sample; $\mathrm{B}=$ Combined Sample 
BRIEF ASSESSMENT OF DISTRESS AND PAIN

Table 16.

\begin{tabular}{cc} 
Discriminant & Validity Correlation Coefficients \\
BADP & FQ-Ag \\
\hline $\begin{array}{c}\text { Fear } \\
\text { Subscale }\end{array}$ & .25 \\
$\begin{array}{c}\text { Anxiety } \\
\text { Subscale }\end{array}$ & .26 \\
$\begin{array}{c}\text { Depression } \\
\text { Subscale }\end{array}$ & .31 \\
Overall \\
$\begin{array}{c}\text { Negative } \\
\text { Affect } \\
\text { Subscale }\end{array}$ \\
Total
\end{tabular}

Note. All correlations were significant at $p<.01$. 
BRIEF ASSESSMENT OF DISTRESS AND PAIN

Table 17.

Factor Loadings from the Principal Components Analysis - Undergraduate Sample.

\begin{tabular}{|c|c|c|c|}
\hline $\begin{array}{c}\text { BADP Item } \\
\#\end{array}$ & $\begin{array}{c}\text { Component } \\
1\end{array}$ & $\begin{array}{c}\text { Component } \\
2\end{array}$ & $\begin{array}{c}\text { Component } \\
3\end{array}$ \\
\hline 1 & - & .71 & - \\
\hline 2 & - & .44 & .68 \\
\hline 3 & - & - & .58 \\
\hline 4 & - & .69 & - \\
\hline 5 & .75 & - & - \\
\hline 6 & .74 & - & .45 \\
\hline 7 & .44 & - & .56 \\
\hline 8 & .58 & .57 & - \\
\hline 9 & .68 & .46 & - \\
\hline 10 & .71 & - & .48 \\
\hline 11 & - & .71 & - \\
\hline 12 & - & - & .79 \\
\hline 13 & .51 & .61 & - \\
\hline 14 & - & - & .73 \\
\hline 15 & .57 & .63 & - \\
\hline 16 & - & .73 & - \\
\hline 17 & .49 & - & .67 \\
\hline 18 & .55 & - & - \\
\hline 19 & .58 & .48 & - \\
\hline 20 & - & - & .69 \\
\hline
\end{tabular}


BRIEF ASSESSMENT OF DISTRESS AND PAIN

Table 18.

Factor Loadings from the Principal Components Analysis - Combined Sample.

\begin{tabular}{|c|c|c|}
\hline $\begin{array}{c}\text { BADP Item } \\
\#\end{array}$ & $\begin{array}{c}\text { Component } \\
1 \\
\end{array}$ & $\begin{array}{c}\text { Component } \\
2 \\
\end{array}$ \\
\hline 1 & .74 & - \\
\hline 2 & .80 & - \\
\hline 3 & .71 & - \\
\hline 4 & .74 & - \\
\hline 5 & .80 & - \\
\hline 6 & .80 & - \\
\hline 7 & .77 & - \\
\hline 8 & .79 & - \\
\hline 9 & .83 & - \\
\hline 10 & .83 & - \\
\hline 11 & .70 & - \\
\hline 12 & .78 & - \\
\hline 13 & .79 & - \\
\hline 14 & .79 & - \\
\hline 15 & .83 & - \\
\hline 16 & .78 & - \\
\hline 17 & .74 & -.42 \\
\hline 18 & .84 & - \\
\hline 19 & .82 & - \\
\hline 20 & .83 & - \\
\hline
\end{tabular}


BRIEF ASSESSMENT OF DISTRESS AND PAIN

Table 19.

Reliability Analysis of the BADP - Undergraduate Sample.

\begin{tabular}{lc}
\hline \multicolumn{1}{c}{ BADP } & Alpha \\
\hline $\begin{array}{l}\text { Fear } \\
\text { subscale }\end{array}$ & .89 \\
Anxiety & \\
subscale & .88 \\
Depression & \\
subscale & .89 \\
Overall & \\
$\begin{array}{l}\text { Negative } \\
\text { Affectivity } \\
\text { subscale }\end{array}$ & .90 \\
Total scale & .96 \\
\hline
\end{tabular}

Note. All alpha values were significant at $p<.001$. 
BRIEF ASSESSMENT OF DISTRESS AND PAIN

Table 20 .

Reliability Analysis of the BADP - Combined Sample

\begin{tabular}{|c|c|}
\hline BADP & \\
\hline & Alpha \\
\hline $\begin{array}{l}\text { Fear } \\
\text { subscale }\end{array}$ & .90 \\
\hline $\begin{array}{l}\text { Anxiety } \\
\text { subscale }\end{array}$ & .90 \\
\hline $\begin{array}{l}\text { Depression } \\
\text { subscale }\end{array}$ & .90 \\
\hline $\begin{array}{l}\text { Overall } \\
\text { Negative } \\
\text { Affectivity } \\
\text { subscale }\end{array}$ & .91 \\
\hline Total scale & .97 \\
\hline
\end{tabular}

Note. All alpha values were significant at $p<.001$. 
BRIEF ASSESSMENT OF DISTRESS AND PAIN

Table 21 .

Final 4-Item Version of the BADP and the Content Validity Ratio of the Selected Items.

\begin{tabular}{|c|c|c|c|c|}
\hline BADP & & & & \\
\hline & $\begin{array}{c}\text { Fear } \\
\text { Sub-Scale }\end{array}$ & $\begin{array}{l}\text { Anxiety } \\
\text { Sub-Scale }\end{array}$ & $\begin{array}{c}\text { Depression } \\
\text { Sub-Scale }\end{array}$ & $\begin{array}{c}\text { ONA } \\
\text { Sub-Scale }\end{array}$ \\
\hline & $\begin{array}{c}\text { 13. I am } \\
\text { scared of } \\
\text { feeling pain. }\end{array}$ & $\begin{array}{l}\text { 11. The fact that I } \\
\text { could feel pain in } \\
\text { the } \\
\text { future worries me } \\
\text { a lot. }\end{array}$ & $\begin{array}{l}\text { 17. Being in pain } \\
\text { makes me feel sad. }\end{array}$ & $\begin{array}{l}\text { 7. Pain causes } \\
\text { me to have } \\
\text { strong negative } \\
\text { feelings }\end{array}$ \\
\hline $\begin{array}{c}\text { CVR } \\
\text { Value }\end{array}$ & .82 & .09 & .82 & .45 \\
\hline
\end{tabular}

Note. ONA $=$ Overall Negative Affect 
BRIEF ASSESSMENT OF DISTRESS AND PAIN

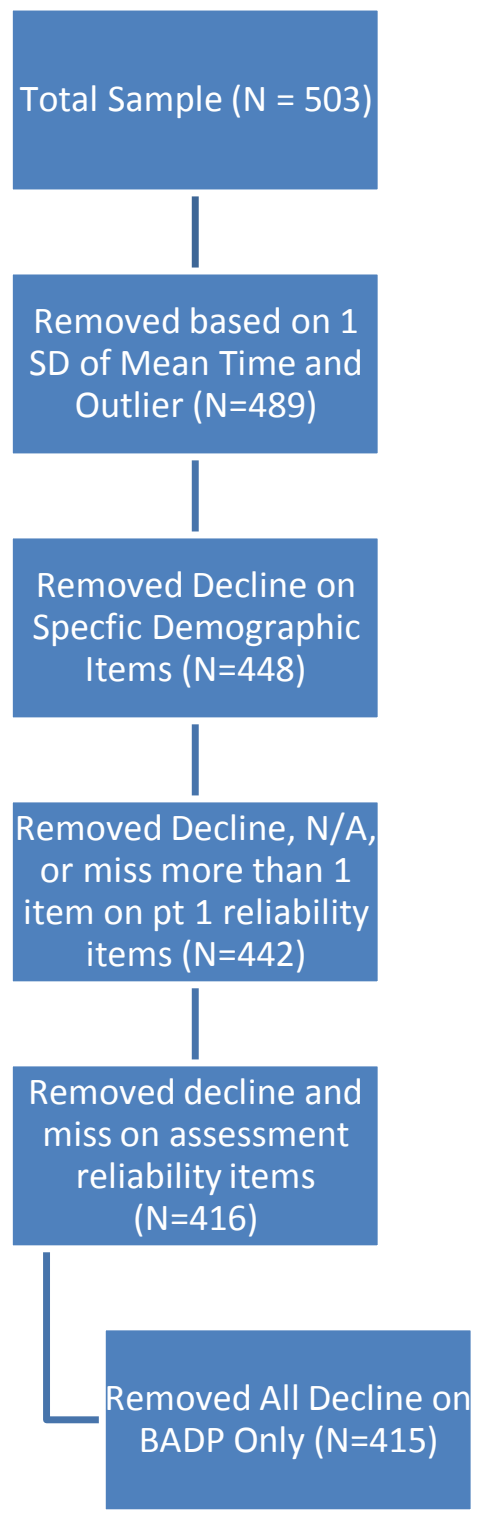

Figure 1. The undergraduate sample participant decision tree for data cleaning and removal. 
BRIEF ASSESSMENT OF DISTRESS AND PAIN

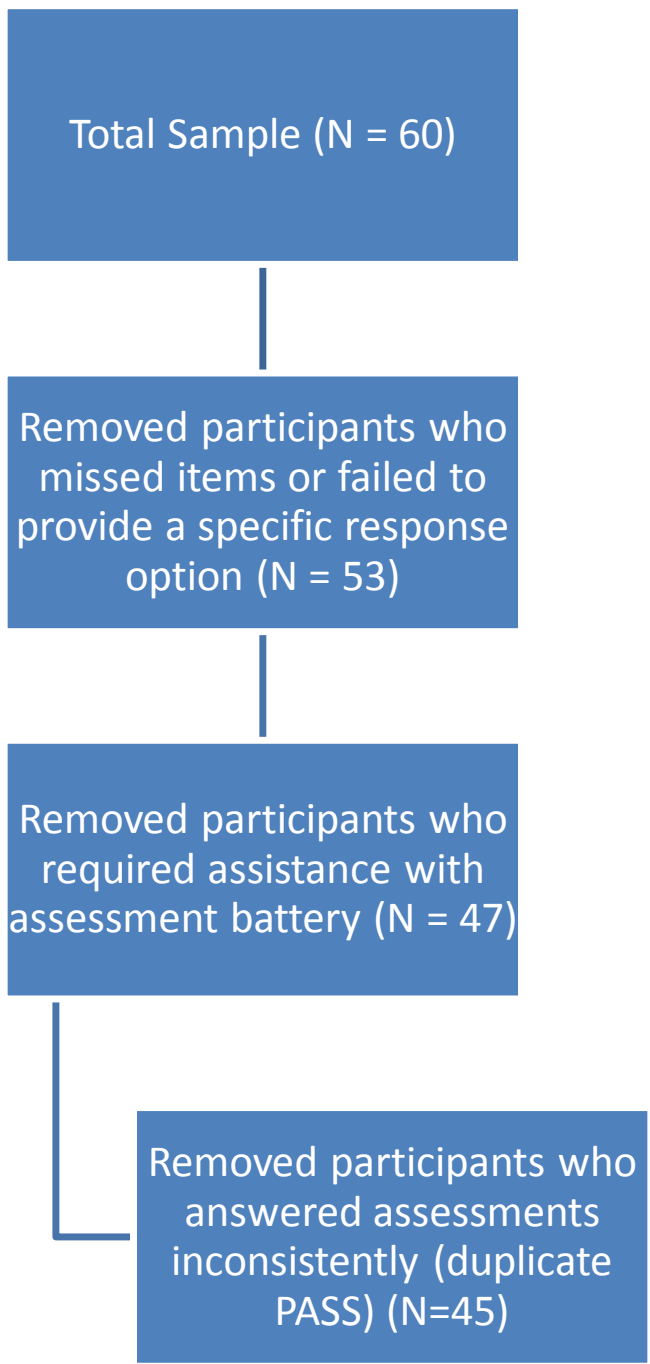

Figure 2. Chronic pain participant decision tree for data cleaning and removal. 
BRIEF ASSESSMENT OF DISTRESS AND PAIN

\section{Appendix A}

Literature Review

\section{Pain}

Chronic pain is a common and costly problem around the world including in the U.S.A. (Gallagher, 1999; Ohayon \& Schatzberg, 2003; Turk, 2006). Chronic pain can result in disability and functional impairment (Gallagher, 1999; Ohayon \& Schatzberg, 2003; Turk, 2006).

Additionally, pain is one of the most common treated by primary care providers (Chronic Pain, 2008). Researchers have found that the greater the intensity of the experience of pain, the greater the likelihood of social and functional disability (Karoly, Okun, Ruehlman, \& Pugliese, 2008). Costs associated with pain treatment were estimated to exceed $\$ 200$ billion, or $1.37 \%$ of the gross domestic product of the U.S.A. in 2010, which was roughly $\$ 14,582,400$, (American Academy of Orthopaedic Surgeons, 2010; World Bank, 2011). Other sources estimated that roughly $\$ 560$ billion to $\$ 635$ billion was spent in treatment related to various pain conditions in the USA in 2010 (American Academy of Pain Medicine, n.d.).

Pain is described as an emotional and sensory experience that is unpleasant, involves tissue damage or the potential for it, or is characterized in terms of this damage (International Association for the Study of Pain, 2011). Pain also has been defined as a sensation that is composed of behavioral, biological, cognitive, affective, and social elements (Bailey, Carleton, Vlaeyen, \& Asmundson, 2010; De Peuter, de Jong, Crombez, \& Vlaeyen, 2009; Mok \& Lee, 2008). There are several distinctions in the types of pain experienced which are not mutually exclusive, some of which are: acute, chronic, nociceptive, and neuropathic pain.

Acute pain. Short term pain or acute pain has been defined as physiological response that is composed of a complex interaction of sensory, psychosocial, and physiological components which usually has an identifiable cause (Keene et al., 2011). It also has been 
BRIEF ASSESSMENT OF DISTRESS AND PAIN

described as having a sudden onset and having a short duration (Carr \& Goudas, 1999). Acute pain functions as a warning or alarm of illness or potential threat to the body, leading to increased attention to the source of pain as well as attempts to protect the injured area and avoidance of future experiences of potential pain (Lumley et al., 2011). Further, acute pain can be quite variable, lasting anywhere from a few moments up to several weeks or even months, typically with fluctuating intensity (Carr \& Goudas, 1999; Zeller, Burke, \& Glass, 2008). Acute pain does not last longer than three to six months; if it persists beyond this point, it is labeled chronic pain (Bruehl \& Chung, 2004). In fact, acute pain is a significant risk factor for the development of chronic pain (Sinatra, 2010). The specific factors that may predispose a person suffering from acute pain to develop chronic pain are not well understood, but there appears to be a significant number of individuals who suffer acute pain associated with surgical procedures and illness who then later develop chronic pain (Sinatra, 2010). Further, the intensity of acute pain experienced after surgical procedures has been found to be a significant risk factor for the development of chronic pain (Sinatra, 2010).

Pain catastrophizing "is characterized by the tendency to magnify the threat value of pain [stimuli] and to feel helpless in the context of pain, and by a realtively inability to inhibit painrelated thoughts in anticipation of, during, of following a painful encounter" (Quartana, Campbell, Edwards, 2009, p. 2). In relation the experience of acute pain, pain catastrophization is thought to lead to persistent pain conditions, greater sensation of pain, and maladjustment (Lumley et al., 2011). Further, high pain catastrophizers who suppress emotions associated with a painful experience are more likely to report pain as more intense and also have delayed recovery from acute pain conditions (Gilliam et al., 2009). Attempts to suppress acute pain have been found to be related to acute pain intensity (Uysal \& Lu, 2011). Specifically, the more one 
BRIEF ASSESSMENT OF DISTRESS AND PAIN

attempts to suppress, the greater the intensity of acute pain (Uysal \& Lu, 2011). Some evidence has indicated that acute and chronic pain may exist along some continuum instead of previous findings indicating that these constructs were separate (Keene et al., 2011). Effectively managing acute pain can lead to more positive outcomes and prevent the progression from acute pain to chronic pain (Sinatra, 2010). Examples of acute pain include labor pain, dental and medical procedures, headaches, broken bones, surgery, and burns or cuts (Bruehl \& Chung, 2004). Acute pain has been found to lead to decreased functionality, impaired social functioning, and decreased reports of quality of life (Sinatra, 2010). Further, the effects of acute pain have been found to impair sleep, mood, sexual functioning, and performance of physical activities (Sinatra, 2010). In relation to medical settings and post-surgical procedures, acute pain has been found to be highly correlated with longer hospital stays and more missed physical therapy sessions (Sinatra, 2010). Acute pain often is prevented or treated through pharmacotherapy, although selfmanagement and behavioral means frequently are utilized (Lumley et al., 2011).

Chronic pain. In contrast to acute pain, chronic pain persists longer than 3-6 months (Harris, 2011; Robinson, 2007). Examples of types of chronic pain are fibromyalgia, arthritis, neurogenic pain, lower back pain, cancer pain, and headache pain (Hadjistavropoulos \& Williams, 2004; Harris, 2011). There are certain presentations of chronic pain that are representative of injury, tissue damage, disease, or trauma, such as joint degeneration, cancer pain, neuropathic pain, and inflammatory diseases (Lumley et al., 2011). Some individuals, however, may suffer from chronic pain in the absence of any past physical injury (Beesdo, Jacobi, Hoyer, Low, Hofler, \& Wittchen, 2010). Chronic pain can be the result of a dysfunction in the neurological alarm system that is characteristic of the response to acute pain and leads to maladaptive behaviors such as avoidance behaviors (Lumley et al., 2011). The transition from 
BRIEF ASSESSMENT OF DISTRESS AND PAIN

acute to chronic pain may be best conceptualized through Gatchel's three stage transitional model of pain (Gatchel \& Dersch, 2002). In this model, the first stage is associated with the emotional consequences of experiencing pain, which is inclusive of anxiety and fear (Gatchel \& Dersch, 2002). If the pain persists two to four months, the individual passes into stage two, which leads to the development and maintenance of maladaptive behavior problems such as depression, anger, learned helplessness, and somatization (Gatchel \& Dersch, 2002). Finally, the individual may move into stage three, which involves the acceptance of a "sick role" thus abstaining from usual activities (Gatchel \& Dersch, 2002). Chronic pain has been associated with serious disability and can cause negative physical effects such as limited mobility, decreased energy, appetite fluctuations, and tense muscles (pain, chronic, 2009; Keene et al., 2011). Certain factors such as numerous surgical procedures, young age, poorly treated pain, and the presence of damage to the nervous system all have been found to be factors that are associated with chronic pain in trauma patients (Keene et al., 2011). Chronic pain patients may make more frequent visits to medical professionals, have high absenteeism from work and other activities, and undergo extensive evaluation procedures for treatment (Asmundson \& Katz, 2009). Chronic pain also has been found to be a significant risk factor for suicide ideation and suicide attempts (Fishbain, Bruns, Disorbio, \& Lewis, 2009a). Emotional and psychological effects of chronic pain include depression, fear, anger, anxiety, anxiety sensitivity, and cognitive catastrophizing (Carleton, Abrams, Kachur, \& Asmundson, 2009; Robinson, 2007).

Nociceptive pain. The acute or short-term period following injury is most representative of nociception (Chronic Pain, 2008). Nociceptive pain is a function of the activation of nociceptors, which are nerves that respond to physical damage or potential damage to the body (Chapman, Nakamura \& Flores, 1999; Gatchel, R. J., 1999). When physical or potential damage 
BRIEF ASSESSMENT OF DISTRESS AND PAIN

triggers nociceptive nerves, the neural signal is transmitted from the peripheral nervous system to the central nervous system, specifically to the brain (Turk \& Flor, 1999). Nociceptive pain is defined as being caused by actual damage to the somatic tissues, but no neural tissue or cells (Keene et al., 2011). When pain persists beyond actual nociceptive input, dysfunction results and the nociceptor(s) are considered to have lost their physiological function and considered to be operating in a maladaptive way (Ruscheweyh, Wilder-Smith, Drdla, Liu, \& Sandkuhler, 2011). Specifically, pain that persists after the healing of an injury is thought to occur due to dysfunctional nociceptors resulting in an alteration of nociceptive input to the central nervous system (Ruscheweyh et al., 2011). Some examples of nociceptive pain include sprains, burns, cuts, muscular tears or strains, bruises, and inflammation (Chapman et al., 1999). Nociceptive pain is time-limited, localized, and is usually constant and of a throbbing, dull, or aching nature (Chapman et al., 1999). Typically, nociceptive pain is highly responsive to treatment with opiate pain medications (Aiello-Laws, Reynolds, Deizer, Peterson, \& Bakitas, 2009).

Neuropathic pain. Neuropathic pain is the malfunction of the nervous system when actual damage has previously occurred; it is considered chronic in nature (Beith, Kemp, Kenyon, Prout \& Chestnut, 2011; Chapman et al., 1999). Generally, neuropathic pain involves some damage to either the central or peripheral nervous system, negatively affecting sensation (Beard \& Aldington, 2011; Harris, 2011; Keene et al., 2011). The pain has been found to persist beyond when the injured area has healed, leading to persistent allodynia (i.e., pain that is elicited by a stimulus that does not typically elicit pain), which is indicative of a malfunctioning nervous system and false alarms (Beard \& Aldington, 2011; Turk \& Flor, 1999). Examples of neuropathic pain include phantom limb pain, post herpetic neuralgia, and carpel tunnel syndrome (Beard \& Aldington, 2011; Harris, 2011). Neuropathic pain has been described as having a 
BRIEF ASSESSMENT OF DISTRESS AND PAIN

burning, shooting, tingling, or electric quality along with numbness and is of a more chronic

nature, lasting numerous months or even years (Beard \& Aldington, 2011; Chapman et al., 1999). In addition, neuropathic pain is less responsive to opiate pain medications and typically is not fully reversible (Polatin \& Gajraj, 2002). Neuropathic pain, however, has been found to be responsive to other pharmaceuticals, such as psychotropic medications (i.e., anti-depressants and anti-seizure medications) (Aiello-Laws et al., 2009; Robinson, 2007; Winteridge, 2009).

\section{Conceptualization of Anxiety, Fear, and Pain}

Although the Fear-Avoidance Model highlights fear specifically, it also can connect fear, anxiety, and depression to pain. In this model, the initial experience of pain is viewed by the individual as catastrophic regardless of its actual intensity (Bailey et al., 2010). For the small portion of individuals that appraise the experience of pain as devastating, catastrophic cognitions relating to the painful experience will develop and negative significance will be attached to the experience of pain and any stimuli associated with the painful experience (Bailey et al., 2010). The presence of catastrophic cognitions and negative significance will then lead to the individual developing what was previously mentioned as fear of pain (Bailey et al., 2010). The experience and maintenance of fear of pain and faulty evaluations or appraisals of the situation increases the chances of developing safety-seeking behaviors such as avoidance and escape behaviors as well increasing one's awareness of the environment and one's somatic and psychological state (Asmundson, Norton, \& Velso, 1999; Bailey et al., 2010; Leeuw et al., 2006).

Fear of pain can be adaptive in cases of acute pain, but generally is maladaptive for the experience of chronic pain (De Peuter et al., 2009; Leeuw et al., 2006). The cycle of avoidance/escape behaviors as well as hypervigiliance prevents or decreases pain experienced in the short-term and thus is self-maintained through negative reinforcement. The formation of this 
BRIEF ASSESSMENT OF DISTRESS AND PAIN

negative, self-maintaining cycle actually exacerbates the experience of pain especially when an injured area has already healed (Asmundson et al., 1999; Keogh \& Mansoor, 2001). Further, avoidance/escape behaviors function to reduce fear in the immediate future whereas in the longterm, these behaviors actually increase the fear associated with potentially painful experiences (Leeuw et al., 2006). Other associated outcomes with this fear-avoidance cycle in relation to the experience of pain are weight gain, muscular atrophy, and decreased mobility (Asmundson et al., 1999). Although this model focuses specifically on fear and pain, the Fear-Avoidance Model also is applicable to depression and anxiety (Bailey et al., 2010; De Peuter et al., 2009). The interaction of fear and avoidance in relation to pain exacerbates the experience of pain, which in turn negatively affects the development and maintenance of anxiety and depression (Bailey et al., 2010; De Peuter et al., 2009).

\section{Relation between Pain and Emotions}

A major component of the experience of pain is emotional distress (Linton \& Shaw, 2011). The relation between pain and emotion is thought to be associated through shared neural connections and activation of the limbic system, specifically the amygdala, through the medial pain system (Linton \& Shaw, 2011; Roy, Piche, Chen, Peretz, \& Rainville, 2009). During the experience of pain, the medial pain system is thought to activate the hippocampus, which may account for the ease of recalling such painful experiences and ultimately, leading to greater escape and avoidance behaviors (Lumley et al., 2011). In addition to activation of similar cortical regions, pain is believed to activate similar pathways that also are associated with the experience of negative emotions (Mitchell \& Harrison, 2010). Further, emotion and pain are thought to affect similar physiological arousal systems including cardiovascular, visual, somatosensory, and 
BRIEF ASSESSMENT OF DISTRESS AND PAIN

auditory systems (Mitchell \& Harrison, 2010). Emotion also affects individuals' cognitions and behaviors in relation the experience of pain (Lumley et al., 2011).

The functional or evolutionary purpose of emotion associated with pain is to increase awareness and to initiate adaptive behaviors (Lumley et al., 2011). The affective-motivational system that is associated with the experience of pain and emotion is thought to be related to activation of defensive behaviors like avoidance and escape to cope with the experience of pain (Lumley et al., 2011). Researchers have found that maladaptive coping strategies associated with emotion and negative affect are related to pain and dysfunction (Lumley et al., 2011). Negative affect, in particular, has been found to be associated with increased suffering associated with painful conditions as well as greater disability and poorer treatment outcomes for individuals who suffer from painful conditions (Linton \& Shaw, 2011; Roy et al., 2009).

In contrast to negative emotional states, positive emotional states have been found to lead to a reduction of pain and better coping strategies (Lumley et al., 2011; Roy et al., 2009). Deficits in emotional awareness may lead to hypervigilance of one's physical being as well as an increase in one's physical sensations, inclusive of the experience of pain (Lumley et al., 2011). The experience of pain also may lead to deficits in emotional functioning (Lumley et al., 2011). In fact, in one study, individuals when exposed to painful stimuli were unable to distinguish between positive and negative affect (Lumley et al., 2011). Ambivalence of emotional expression, "the desire to express emotion, yet the fear of doing so," leads to greater experiences of pain and poorer quality of life (Lumley et al., 2011, p. 950).

In light of these findings, negative emotional states are thought to exacerbate pain primarily in situations in which the individual is highly aroused by the painful experience (Lumley et al., 2011). This phenomenon, however, may also be conceptualized as a bi- 
BRIEF ASSESSMENT OF DISTRESS AND PAIN

directional interaction between emotion and pain in which pain also can negatively influence an individual's emotional state. The suppression of emotion, specifically anger, is associated with the exacerbation of the experience of pain, heightened pain sensitivity, lower pain tolerance, (Lumley et al., 2011; Quartana, Bounds, Yoon, Goodin, \& Burns, 2010). It is believed that negative affect may play a role in the relationship between suppression of emotion (e.g., anger) and the experience of pain (Quartana et al., 2010). In reference to the interaction of emotions and pain, some of the most common emotional reactions that are highly associated with experience of pain are depression, anxiety, fear, guilt, anger, and frustration (Linton \& Shaw, 2011).

\section{Fear}

In relation to pain, fear is a multidimensional state that is a complex composition of catastrophizing about bodily cues, fear of re-injury, and beliefs that avoidance/escape behaviors of potentially painful experiences will prevent the experience of pain in the future (Karoly et al., 2008). Others have defined fear as a "mobilization for avoidance/escape and other responses" (McNeil \& Rainwater, 1998, p. 390). Fear of pain, more specifically, is defined as “...an excessive, irrational, and debilitating fear of physical movement and activity, resulting in fears of vulnerability to painful injury or (re)injury" (Reneman, Schiphorts, Kleen, Geertzen, \& Dijkstra, 2007, p. 248). Fear is a component of the fight or flight response of the autonomic nervous system which is activated when a threat is detected (Craske, 2003). Fear, a more immediate response to the experience of pain, occurs in close proximity of the actual experience of pain and leads to avoidance and escape behaviors (Bailey et al., 2009; Craske, 2003). Fear functions as a protective state from actual or potential threats through the development of avoidance behaviors which leads to improved survival (Craske, 2003). Due to the automatic nature of the fear response, there is a limited depth of cognitive processing that occurs when fear is initially 
BRIEF ASSESSMENT OF DISTRESS AND PAIN

activated, which decreases higher level cognitive processes such as judgment (Craske, 2003).

Due to the lack of advanced cognitive processes, fear, originally an adaptive mechanism, can be incorporated in the development and maintenance of pain (Dehghani, Sharpe, \& Nicholas, 2010; Vowles, McNeil, Sorrell, \& Lawrence, 2006).

The development of pain-related fear can develop through the actual experience of pain (Bailey et al., 2009). Fear of re-injury or exacerbation of the sensation of pain that is associated with the experience of chronic pain in particular can be quite debilitating, leading to avoidance of normal activities such as work and enjoyable hobbies (Gatchel \& Dersch, 2002; Karoly et al., 2008; Robinson, 2007). Individuals who have high levels of fear also are more likely to overpredict future painful experiences, report greater intensities of pain, and perceive greater disability associated with pain (De Peuter et al., 2009). High levels of fear also have been found to be associated with decreased physical performance on tasks, decreased participation in activities, and poorer treatment performance (Asmundson et al., 1999; De Peuter et al., 2009).

\section{Pain catastrophizing}

A central component in the development of fear of pain may be the catastrophizing cognitions associated with the occurrence of pain (De Peuter et al., 2009). The cognitive phenomenon of pain catastrophizing is a component of fear of pain and has been found to be associated with increased reports of pain, use of pain medication, pain related distress and disability (Dehghani et al., 2010; De Peuter et al., 2009). Pain catastrophizing has been found to be related to the intensity of pain for individuals suffering from acute pain conditions (Gilliam et al., 2010). For chronic pain suffers, pain catastrophizing has been found to negatively influence the severity of the experience of pain, adjustment, and emotional distress associated with pain (Gilliam et al., 2010). Further, individuals who are classified as high pain catastrophizers are 
BRIEF ASSESSMENT OF DISTRESS AND PAIN

more likely to attempt to suppress their emotions and awareness of pain due to the overwhelming nature of the experience of pain, which ultimately leads to an exacerbation of the experience of pain and delays recovery (Gilliam et al., 2009).

Pain catastrophizing also has been found to be a significant risk factor for suicide ideation (Fishbain et al., 2009a). Catastrophizing cognitions also are significant component in the development of fear of re-injury, another component of fear of pain (De Peuter et al., 2009). The compounded effect of pain-related fear and cognitive catastrophizing can lead to the development of avoidance and escape behaviors from tasks that are appraised as potentially painful, resulting in overall distress and poor outcomes (Karoly et al., 2008; Leeuw et al., 2007; Lumley et al., 2011; Reneman et al., 2007). Hypervigilance, an acute awareness of one’s physical and psychological state, can compound the relation between pain catastrophizing cognitions and reported pain, making avoidance behaviors more likely (Leeuw et al., 2007; Reneman et al., 2007). Hypervigilance also can lead to negative effects on individuals who suffer from pain (Leeuw et al., 2007; Reneman et al., 2007). Hypervigilance is a top-down process which is automatic in nature and limits ability to cope with the experience of pain in more effective ways (De Peuter et al., 2009). Also, the greater the experience of pain, the more likely the individual will become hypervigilant of somatic sensations (White et al., 2009).

\section{Hypochondriasis}

According to the Diagnostic and Statistical Manual of Mental Disorders-V (DSM-V), hypochondriasis is composed of an intense fear and belief of having a serious disease or healthrelated problem that is based on a misinterpretation of bodily cues and persists after reassurance from medical professionals (American Psychiatric Association, 2013). Health anxiety, also known more formally as hypochondriasis, is a function of cognitive catastrophication of health 
BRIEF ASSESSMENT OF DISTRESS AND PAIN

and somatic information and cues (Rode, Salkovskis, Dowd, \& Hanna, 2006). Chronic pain has been found to be associated with hypochondriasis (Rode et al., 2006).

According to Glenton (2003), there appears to be concern (e.g., fear) among many back pain sufferers about the degree to which medical staff and others question the legitimacy of their pain. The difficulty in determining the cause of back pain can make circumstances generally more challenging for suffers of chronic back pain (Glenton, 2003). When the cause of pain is more difficult to diagnose, individuals suffering from pain will seek assistance from health professionals to determine an organic cause of the pain (Glenton, 2003).

Individuals suffering from back pain in which the cause of the pain is difficult to determine are less likely to accept psychological explanations of their pain (Glenton, 2003). Their unwillingness to accept psychological causes of their pain may be attributable to the potential stigma that may be attached to them if the cause of the pain is found to be predominately or solely psychological (Glenton, 2003). Visible proof (e.g., casts, crutches, braces, etc.) of one's ailments appears to assist in confirming one's condition to others and thus is reinforcing (Glenton, 2003).

Somatization is associated with multiple, frequent physical issues that have no medical explanation and lead one to seek medical treatment (American Psychiatric Association, 2013). Somatization, in contrast to hypochondriasis, requires more physiological or psychological complaints that focus on one's entire body. Hypochondriasis can be viewed by some as being encompassed within a diagnosis of somatization (Fishbain, Lewis, Gao, Cole, \& Rosomoff, 2009b; Lipowski, 1988). Somatization has been found to be highly associated with hypochondriasis and chronic pain (Fishbain et al., 2009b). Pain intensity also appears to play a significant role in the associations between chronic pain, somatization, and hypochondriasis 
BRIEF ASSESSMENT OF DISTRESS AND PAIN

(Fishbain et al., 2009b; Rode et al., 2009). In addition emotional states such as anxiety and depression have been linked to chronic pain, somatization, and hypochondriasis (Fishbain et al., 2009b; Lipowski, 1988).

\section{Anxiety and Anxiety Sensitivity}

Anxiety is one of the most studied psychological constructs associated with pain (Mok \& Lee, 2008). It is common to find anxiety present even when the onset of pain is fairly recent (Cleeland, 1986). Studies have found a high degree of comorbidity between the experience of pain and anxiety disorders such as generalized anxiety disorder, social anxiety disorder, posttraumatic stress disorder, and panic disorder (Asmundson \& Katz, 2009; Beesdo et al., 2008). Individuals who suffer from chronic pain are more likely to develop anxiety disorders than individuals without pain (Linton \& Shaw, 2011). Anxiety, in relation to the experience of chronic pain, often is more of a diffuse, response to the experience of pain and can increase withdrawal behaviors (Bailey et al., 2009; McNeil \& Rainwater, 1998).

In general, there is usually a great deal of ambiguity in the conceptualizations of anxiety and fear. These states often are confused, especially in reference to the experience of pain. Although seemingly similar, fear or panic is qualitatively different from anxiety or worry (Craske, 2003). In fact, they may even be mutually exclusive (Craske, 2003). Fear and anxiety activate different response systems that are based on the imminence of the threat (Craske, 2003). In contrast to fear, anxiety has been described as more of a diffuse reaction to future-oriented events (Craske, 2003; Leeuw et al., 2007). More specifically, anxiety is a "diffuse reaction pattern...[including]...responses such as worry that require less visceral organization and activity" (McNeil \& Rainwater, 1998, p. 390). Anxiety related to the experience of pain has been found to be in anticipation of a nociceptive stimulation (Bailey et al., 2009). The purpose of 
BRIEF ASSESSMENT OF DISTRESS AND PAIN

anxiety is to prepare and plan for any potential threats (Craske, 2003). Anxiety functions as a means of attempting to gain certainty and is associated with reduced autonomic arousal, lower skin conductance, and heart rate variability (Craske, 2003). Anxiety also has been found to affect the experience and maintenance of pain, disability associated with pain, and the chronicity of pain (Mok \& Lee, 2008). Anxiety can lead to greater perceptions of future painful experiences and over-predictions of new experiences of pain (Bailey et al., 2010; Vadalouca et al., 2009). Anxiety also is a predictor of pain intensity (Mok \& Lee, 2008; Vadalouca et al., 2009). The presence of anxiety and pain in addition to depression has been found to be associated with greater disability, increased likelihood of substance use, and decreased quality of life (Beesdo et al., 2008).

Research suggests chronic pain is associated with anxiety sensitivity (Uman, Stewart, Watt, \& Johnston, 2006). Anxiety sensitivity has been defined as the fear of anxiety-related physiological and psychological arousal symptoms (Asmundson \& Katz, 2009). Evidence suggests that anxiety sensitivity may exacerbate the experience of pain (Stewart \& Asmundson, 2006). It is believed that anxiety sensitivity and the experience of pain are connected through higher levels involving body vigilance or hypervigilance (White, Craft, \& Gervino, 2009). Specifically, individuals with a high degree of anxiety sensitivity will be more likely to interpret somatic symptoms, such as pain, negatively (Asmundson \& Norton, 1995). In addition to high degrees of body vigilance, individuals who experience high levels of anxiety sensitivity are more likely to have increased avoidance and anxiety-related escape behaviors which can be compounded further by the experience of pain (Asmundson \& Taylor, 1996; Norton \& Asmundson, 2004). High anxiety sensitivity has also been found to be associated with greater degrees of reported pain and cognitive anxiety leading to the development of pain-related 
BRIEF ASSESSMENT OF DISTRESS AND PAIN

catastrophizing cognitions and fearful appraisals of situations and stimuli (Watt, Stewart,

Lefaivre, \& Uman, 2006). Factors that are strongly associated with anxiety sensitivity and pain are fear of potentially painful experiences, greater avoidance behaviors, and greater sensitivity to overall arousal symptoms are those which are more likely to lead to poorer outcomes for individuals suffering from pain (Asmundson \& Taylor, 1996; Watt et al., 2006).

\section{Depression}

Besides anxiety, depression is one of the most studied variables within the realm of pain related research (Mok \& Lee, 2008). Approximately 50 to $65 \%$ of depressed individuals suffer from comorbid pain conditions (DeVeaugh-Geiss et al., 2010; Poleshuck et al., 2010). These same individuals present with more somatic than psychological complaints (DeVeaughGeiss et al., 2010; Poleshuck et al., 2010). In addition, approximately $21 \%$ of chronic pain patients present with a comorbid diagnosis of depression (Schattner \& Shahar, 2011). Chronic pain has been found to be highly associated with the development of depression (Cleeland, 1986). Lerman, Shahar, and Rudich (2010) define depression as a complex composition of somatic, cognitive, and affective constituents which results in sleep pattern changes, weight change, negative affect, fatigue, loss of interest in activities, and interpersonal difficulties. Depression has been found to affect both the chronicity and reoccurrence of pain (Mok \& Lee, 2008). The comorbidity of pain and depression lead to decreased functionality, decreased quality of life, poor interpersonal relationships, and over-utilization of health care (Ang et al., 2010; DeVeaugh-Geiss et al., 2010; Poleshuck et al., 2010). Individuals with both depression and pain are generally less responsive to various treatment methodologies, which can lead to poorer outcomes in comparison to individuals suffering only from depression or pain (Ang et al., 2010; Poleshuck et al., 2010; Schattner \& Shahar, 2011). The magnitude of depressive symptoms in 
BRIEF ASSESSMENT OF DISTRESS AND PAIN

addition to the experience of pain is a significant predictor of suicidal ideation (Fishbain et al., 2009a). When pain conditions are managed or treated effectively, comorbid depression symptomatology typically improves, and can be dramatic (DeVeaugh-Geiss et al., 2010). Some findings indicate that depression increases the chances of the development of pain-related conditions whereas others indicate pain as the predisposing factor to the development and maintenance of depression (Ang et al., 2010; Gatchel \& Dersch, 2002). Like anxiety and fear, the relation between pain and depression is complex and likely multi-directional. The specific variables that account for the high degree of comorbidity of depression and pain are difficult to tease apart (Cleeland, 1986; Lerman et al., 2010). Some researchers hypothesize that both depression and pain share several factors, specifically affective and somatic components, which may partially account for the relation (Harris, 2011; Lerman et al., 2010). Further, studies have shown depression and pain share common neurological pathways (Lerman et al., 2010).

\section{Conclusions}

Pain can be viewed as an adaptive response in the short-term whereas over an extended period of time, the response becomes maladaptive. Emotions have been found to be highly related to the experience of pain. The conceptualizations of pain and emotion have evolved over time with current theory emphasizing the multi-directional nature of their relations. Various emotional conditions such as fear, anxiety, and depression have been found to be related to pain, such that these emotional conditions can exacerbate the negative effects of the experience of pain. This literature review highlights the importance of the consideration of emotion in addition to the experience of pain. 
BRIEF ASSESSMENT OF DISTRESS AND PAIN

\section{Appendix B}

Letter to Expert Judges

October 4, 2012

Dear

I am asking for your help with my Master's thesis project. I am developing a 4 item assessment which will be utilized in assessing anxiety, fear, depression, and overall negative affectivity in relation to pain. Ultimately, I am hoping to identify a single item that can be used to assess negative affect about pain. In order to evaluate the content of the assessment items early in the developmental phase, an expert review process has been incorporated. I request that you offer your opinion about the relevance of each of the items for measuring each construct in relation to pain. This should be a relatively brief endeavor of 10-30 minutes, but your professional judgment, comments, and suggestions would be of great benefit to me.

I am asking you to evaluate items that relate to anxiety, fear, and depression, as well as items about negative affect in general. I want to add one brief note about the distinction between anxiety and fear. Anxiety will be operationally defined as more of a diffuse reaction to futureoriented events whereas fear is operationally defined as a more immediate response to the experience of pain and typically occurs in close proximity of the actual experience of pain. Depression will be operationally defined as a complex composition of somatic, cognitive, and affective components which can result in various negative effects (i.e., sleep pattern changes, weight change, negative affect, fatigue, loss of interest in activities, and interpersonal difficulties). The relationship between pain and these negative affective states is classified as complex such that these negative affective states can exacerbate pain and pain can exacerbate these negative affective states. The psychological variables mentioned above have been found to negatively affect patient responses to pain treatment as well. Numerous assessments that assess anxiety, fear, depression, or pain have already been developed. There is, however, a paucity of measures which assess all of these constructs in one scale and even fewer that are brief in length. Brevity of assessment is crucial in medical, dental, and clinical settings. The ultimate goal of this study is to design a brief (i.e., 4 item scale) in which one item will be utilized to assess each construct. This brief assessment will be useful in a variety of healthbased settings.

I am hoping that you would be willing to participate in the expert review. The attached document titled "A Brief Assessment of Distress and Pain - Ratings by Expert Judges" provides instructions and spaces for providing feedback both on individual items. The statistical analysis only requires 8 experts to do ratings, so you are part of a select group, and your involvement will be much appreciated. You can respond on paper or via e-mail, whichever is easier for you. 
BRIEF ASSESSMENT OF DISTRESS AND PAIN

In research such as this project, WVU's institutional review board has deemed that an expert review process is in itself not considered human subjects research, and hence is not subject to IRB review or informed consent.

If possible, please respond in the next 2 weeks (October $18^{\text {th }}$ ). We are hoping to begin data collection in the near future. Thank you very much for your time and consideration. If you have any questions or concerns, please contact me at lquentin@mix.wvu.edu or my dissertation chair, Dr. Daniel W. McNeil, at Daniel.McNeil@mail.wvu.edu. You also may send the completed review to me at my e-mail address, or at PO Box 6040, Department of Psychology, West Virginia University, Morgantown, WV 26506-6040 USA. Thank you again.

Sincerely,

Laura Quentin

Doctoral Student in Clinical Psychology

West Virginia University 
BRIEF ASSESSMENT OF DISTRESS AND PAIN

\section{Appendix C}

\section{Fear of Pain Questionnaire-III (FPQ-III)}

The items listed below describe painful experiences. Please look at each item and think about how FEARFUL you are of experiencing the PAIN associated with each item. If you have never experienced the PAIN of a particular item, please answer on the basis of how FEARFUL you expect you would be if you had such an experience. Fill in one circle for each item below to rate your FEAR OF PAIN in relation to each event.

\begin{tabular}{|c|c|c|c|c|c|}
\hline & $\begin{array}{l}\text { Not At } \\
\text { All }\end{array}$ & A Little & $\begin{array}{l}\text { A Fair } \\
\text { Amount }\end{array}$ & $\begin{array}{l}\text { Very } \\
\text { Much }\end{array}$ & Extreme \\
\hline 1. Being in an automobile accident. & o & o & 0 & 0 & 0 \\
\hline 2. Biting your tongue while eating. & o & 0 & 0 & 0 & 0 \\
\hline 3. Breaking your arm. & 0 & 0 & 0 & 0 & 0 \\
\hline 4. Cutting your tongue licking an envelope. & 0 & 0 & 0 & 0 & 0 \\
\hline 5. Having a heavy object hit you in the head. & 0 & 0 & 0 & $\circ$ & 0 \\
\hline 6. Breaking your leg. & o & 0 & 0 & 0 & 0 \\
\hline $\begin{array}{l}\text { 7. Hitting a sensitive bone in your elbow - } \\
\text { your "funny bone." }\end{array}$ & 0 & 0 & 0 & 0 & 0 \\
\hline $\begin{array}{l}\text { 8. Having a blood sample drawn with a } \\
\text { hypodermic needle. }\end{array}$ & 0 & 0 & ○ & ○ & o \\
\hline $\begin{array}{l}\text { 9. Having someone slam a heavy car door } \\
\text { on your hand. }\end{array}$ & ○ & ○ & o & o & o \\
\hline 10. Falling down a flight of concrete stairs. & o & 0 & $\circ$ & o & 0 \\
\hline 11. Receiving an injection in your arm. & 0 & 0 & 0 & 0 & 0 \\
\hline 12. Burning your fingers with a match. & 0 & 0 & o & 0 & 0 \\
\hline 13. Breaking your neck. & o & 0 & o & o & o \\
\hline $\begin{array}{l}\text { 14. Receiving an injection in your } \\
\text { hip/buttocks. }\end{array}$ & 0 & 0 & 0 & 0 & 0 \\
\hline $\begin{array}{l}15 . \text { Having a deep splinter in the sole of } \\
\text { your foot probed and removed with } \\
\text { tweezers. }\end{array}$ & 0 & 0 & 0 & 0 & 0 \\
\hline
\end{tabular}


BRIEF ASSESSMENT OF DISTRESS AND PAIN

\begin{tabular}{|c|c|c|c|c|c|}
\hline & $\begin{array}{l}\text { Not At } \\
\text { All }\end{array}$ & A Little & $\begin{array}{l}\text { A Fair } \\
\text { Amount }\end{array}$ & $\begin{array}{l}\text { Very } \\
\text { Much }\end{array}$ & Extreme \\
\hline $\begin{array}{l}\text { 16. Having an eye doctor remove a foreign } \\
\text { particle stuck in your eye. }\end{array}$ & O & O & O & O & O \\
\hline 17. Receiving an injection in your mouth. & O & O & O & O & ○ \\
\hline $\begin{array}{l}\text { 18. Being burned on your face by a lit } \\
\text { cigarette. }\end{array}$ & O & O & O & O & O \\
\hline 19. Getting a paper-cut on your finger. & 0 & 0 & 0 & 0 & 0 \\
\hline 20. Receiving stitches in your lip. & 0 & 0 & 0 & 0 & 0 \\
\hline $\begin{array}{l}\text { 21. Having a foot doctor remove a wart from } \\
\text { your foot with a sharp instrument. }\end{array}$ & O & O & O & O & O \\
\hline $\begin{array}{l}\text { 22. Cutting yourself while shaving with a } \\
\text { sharp razor. }\end{array}$ & o & O & O & O & O \\
\hline 23. Gulping a hot drink before it has cooled. & ○ & O & O & O & o \\
\hline $\begin{array}{l}\text { 24. Getting strong soap in both your eyes } \\
\text { while bathing or showering. }\end{array}$ & O & O & O & O & O \\
\hline $\begin{array}{l}\text { 25. Having a terminal illness that causes you } \\
\text { daily pain. }\end{array}$ & O & O & O & O & O \\
\hline 26. Having a tooth pulled. & ○ & o & O & O & o \\
\hline $\begin{array}{l}\text { 27. Vomiting repeatedly because of food } \\
\text { poisoning. }\end{array}$ & ○ & ○ & O & O & O \\
\hline 28. Having sand or dust blow into your eyes. & O & O & O & O & O \\
\hline 29. Having one of your teeth drilled. & ○ & ○ & O & O & O \\
\hline 30. Having a muscle cramp. & 0 & 0 & 0 & 0 & 0 \\
\hline
\end{tabular}

*Note. Item 10 was repeated at the end of the FPQ-III in the assessment battery. 
BRIEF ASSESSMENT OF DISTRESS AND PAIN

Appendix D

Pain Anxiety Symptoms Scale (PASS)

\begin{tabular}{cccccc}
0 & 1 & 2 & 3 & 4 & 5 \\
\hline Never & & & Always
\end{tabular}

- 1. I think that if my pain gets too severe, it will never decrease.

- 2. My mind is calm when I am in pain.

- $\quad 3$. When I feel pain I try to stay as still as possible.

- 4. I become sweaty when in pain.

- 5. When I feel pain, I am afraid something terrible will happen.

- 6. My thoughts are agitated and keyed up as pain approaches.

- 7. I go immediately to bed when I feel severe pain.

- 8. Even though it hurts, I know that I'm going to be O.K.

- 9. My body gets shaky when I hurt.

- 10. I feel disoriented and confused when I hurt.

- 11. When pain gets severe, I call my doctor or go to the emergency room.

- $\quad 12$. I begin trembling when engaged in an activity that increases pain.

- 13. When I feel pain, I become afraid of dying.

- 14. I can't think straight when in pain.

- $\quad$ 15. I will stop an activity as soon as I sense pain coming on.

- 16. Even if I do an activity which causes pain, I know it will decrease later.

- 17. Pain seems to cause my heart to pound or race.

- 18 . I think that I have a serious medical problem that my physician has failed to uncover.

- 19. As soon as pain comes on I take medication to reduce it.

- 20. I have pressure or tightness in my chest when in pain. 
BRIEF ASSESSMENT OF DISTRESS AND PAIN

\begin{tabular}{cccccc}
0 & 1 & 2 & 3 & 4 & 5 \\
\hline Never & & & & Always
\end{tabular}

- $\quad$ 21. When I feel pain I think that I might be seriously ill.

_ 22. During painful episodes it is difficult for me to think of anything besides the pain.

- 23. I avoid important activities when I hurt.

- 24. When I sense pain, I feel dizzy or faint.

- 25. Pain sensations are terrifying.

- 26. When I hurt, I think about the pain constantly.

- 27. I take medication if I know that I need to do something which usually increases pain.

_ $\quad$ 28. I have trouble catching my breath when I have pain sensations.

_ 29. I dread feeling pain.

- 30. I am bothered by unwanted thoughts when I'm in pain.

- 31. If a chance comes to do something I enjoy, I do it even if it causes pain.

- 32. Pain makes me nauseous.

- 33. When pain comes on strong, I think that I might become paralyzed or more disabled.

- 34. I find it hard to concentrate when I hurt.

- 35. I seek reassurance that I am OK during times of more severe pain.

- 36. I find it difficult to calm my body down after periods of pain.

_ 37. I worry when I am in pain.

- 38. My stomach bothers me when I experience pain.

- 39. I try to avoid activities that cause pain.

_ $\quad 40$. I can think pretty clearly even while experiencing severe pain. 


\section{Appendix E}

\section{Anxiety Sensitivity Index-3 (ASI-3)}

Please circle the number that best corresponds to how much you agree with each item. If any items concern something that you have never experienced (e.g., fainting in public) answer on the basis of how you think you might feel if you had such an experience. Otherwise, answer all items on the basis of your own experience. Be careful to circle only one number for each item and please answer all items.

\begin{tabular}{|c|c|c|c|c|c|}
\hline & $\begin{array}{l}\text { Very } \\
\text { Little }\end{array}$ & A little & Some & Much & $\begin{array}{l}\text { Very } \\
\text { much }\end{array}$ \\
\hline $\begin{array}{l}\text { 1. It is important for me not to appear } \\
\text { nervous. }\end{array}$ & 0 & 1 & 2 & 3 & 4 \\
\hline $\begin{array}{l}\text { 2. When I cannot keep my mind on a } \\
\text { task, I worry that I might be going } \\
\text { crazy. }\end{array}$ & 0 & 1 & 2 & 3 & 4 \\
\hline $\begin{array}{l}3 \text {. It scares me when my heart beats } \\
\text { rapidly. }\end{array}$ & 0 & 1 & 2 & 3 & 4 \\
\hline $\begin{array}{l}\text { 4. When my stomach is upset, I worry } \\
\text { that I might be seriously ill. }\end{array}$ & 0 & 1 & 2 & 3 & 4 \\
\hline $\begin{array}{l}\text { 5. It scares me when I am unable to } \\
\text { keep my mind on a task. }\end{array}$ & 0 & 1 & 2 & 3 & 4 \\
\hline $\begin{array}{l}\text { 6. When I tremble in the presence of } \\
\text { others, I fear what people might think } \\
\text { of me. }\end{array}$ & 0 & 1 & 2 & 3 & 4 \\
\hline $\begin{array}{l}\text { 7. When my chest feels tight, I get } \\
\text { scared that I won't be able to breathe } \\
\text { properly. }\end{array}$ & 0 & 1 & 2 & 3 & 4 \\
\hline $\begin{array}{l}8 . \text { When I feel pain in my chest, I } \\
\text { worry that I am going to have a heart } \\
\text { attack. }\end{array}$ & 0 & 1 & 2 & 3 & 4 \\
\hline $\begin{array}{l}\text { 9. I worry that other people will } \\
\text { notice my anxiety. }\end{array}$ & 0 & 1 & 2 & 3 & 4 \\
\hline $\begin{array}{l}\text { 10. When I feel "spacey" or spaced } \\
\text { out I worry that I may be mentally ill. }\end{array}$ & 0 & 1 & 2 & 3 & 4 \\
\hline
\end{tabular}


BRIEF ASSESSMENT OF DISTRESS AND PAIN

\begin{tabular}{|l|c|c|c|c|c|}
\hline & $\begin{array}{c}\text { Very } \\
\text { little }\end{array}$ & A little & Some & Much & $\begin{array}{c}\text { Very } \\
\text { much }\end{array}$ \\
\hline $\begin{array}{l}\text { 11. It scares me when I blush in front } \\
\text { of people. }\end{array}$ & 0 & 1 & 2 & 3 & 4 \\
\hline $\begin{array}{l}\text { 12. When I notice my heart skipping a } \\
\text { beat, I worry that there is something } \\
\text { seriously wrong with me. }\end{array}$ & 0 & 1 & 2 & 3 & 4 \\
\hline $\begin{array}{l}\text { 13. When I begin to sweat in a social } \\
\text { situation, I fear people will think } \\
\text { negatively of me. }\end{array}$ & 0 & 1 & 2 & 3 & 4 \\
\hline $\begin{array}{l}\text { 14. When my thoughts seem to speed } \\
\text { up, I worry that I might be going } \\
\text { crazy. }\end{array}$ & 0 & 1 & 2 & 3 & 4 \\
\hline $\begin{array}{l}\text { 15. When my throat feels tight, I } \\
\text { worry that I could choke to death. }\end{array}$ & 0 & 1 & 2 & 3 & 4 \\
\hline $\begin{array}{l}\text { 16. When I have trouble thinking } \\
\text { clearly, I worry that there is } \\
\text { something wrong with me. }\end{array}$ & 0 & 1 & 2 & 3 & 4 \\
\hline $\begin{array}{l}\text { 17. I think it would be horrible for me } \\
\text { to faint in public. }\end{array}$ & 0 & 1 & 2 & 3 & 4 \\
\hline $\begin{array}{l}\text { worry there is something terribly } \\
\text { wrong me. }\end{array}$ & 0 & & & & \\
\hline
\end{tabular}




\section{Appendix F}

Tampa Scale for Kinesiophobia (TSK-11)

Instructions: These situations may or may not apply to you so you may wish to either select disagree or strongly disagree. Other questions ask you about your beliefs so you may answer them accordingly.

\begin{tabular}{|c|c|c|c|c|}
\hline & $\begin{array}{l}\text { Strongly } \\
\text { Disagree }\end{array}$ & Disagree & Agree & $\begin{array}{l}\text { Strongly } \\
\text { Agree }\end{array}$ \\
\hline $\begin{array}{l}\text { 1. I'm afraid } \\
\text { that I might } \\
\text { injury myself if } \\
\text { I exercise. }\end{array}$ & 1 & 2 & 3 & 4 \\
\hline $\begin{array}{l}\text { 2. If I were to } \\
\text { try to overcome } \\
\text { it, my pain } \\
\text { would increase. }\end{array}$ & 1 & 2 & 3 & 4 \\
\hline $\begin{array}{l}\text { 3. My body is } \\
\text { telling me I have } \\
\text { something } \\
\text { dangerously } \\
\text { wrong. }\end{array}$ & 1 & 2 & 3 & 4 \\
\hline $\begin{array}{l}\text { 4. People aren't } \\
\text { taking my } \\
\text { medical } \\
\text { condition } \\
\text { seriously } \\
\text { enough. }\end{array}$ & 1 & 2 & 3 & 4 \\
\hline $\begin{array}{l}\text { 5. My accident } \\
\text { has put my body } \\
\text { at risk for the } \\
\text { rest of my life. }\end{array}$ & 1 & 2 & 3 & 4 \\
\hline $\begin{array}{l}\text { 6. Pain always } \\
\text { means I have } \\
\text { injured my body. }\end{array}$ & 1 & 2 & 3 & 4 \\
\hline
\end{tabular}


BRIEF ASSESSMENT OF DISTRESS AND PAIN

\begin{tabular}{|c|c|c|c|c|}
\hline $\begin{array}{l}\text { 7.Simply being } \\
\text { careful that I do } \\
\text { not make any } \\
\text { unnecessary } \\
\text { movements is } \\
\text { the safest thing I } \\
\text { can do to } \\
\text { prevent my pain } \\
\text { from worsening. }\end{array}$ & 1 & 2 & 3 & 4 \\
\hline $\begin{array}{l}8 . \text { I wouldn't } \\
\text { have this much } \\
\text { pain if there } \\
\text { weren't } \\
\text { something } \\
\text { potentially } \\
\text { dangerous going } \\
\text { on in my body. }\end{array}$ & 1 & 2 & 3 & 4 \\
\hline $\begin{array}{l}\text { 9. Pain lets me } \\
\text { know when to } \\
\text { stop exercising } \\
\text { so that I don't } \\
\text { injure myself. }\end{array}$ & 1 & 2 & 3 & 4 \\
\hline $\begin{array}{l}\text { 10. I can't do all } \\
\text { the things } \\
\text { normal people } \\
\text { do because it's } \\
\text { too easy for me } \\
\text { to get injured. }\end{array}$ & 1 & 2 & 3 & 4 \\
\hline $\begin{array}{l}\text { 11. No one } \\
\text { should have to } \\
\text { exercise when } \\
\text { he/she is in pain }\end{array}$ & 1 & 2 & 3 & 4 \\
\hline
\end{tabular}

*Note. Item 3 was repeated at the end of the TSK-11 in the assessment battery. 
BRIEF ASSESSMENT OF DISTRESS AND PAIN

\section{Appendix G}

Fear-Avoidance Beliefs Questionnaire (FABQ)

Instructions: Here are some of the things that patients with back pain have told us about their pain. For each statement please circle the number from 0 to 6 to say how much physical activities such as bending, lifting, walking, or driving would affect you if you had back pain.

$\begin{array}{ccccccc}0 & 1 & 2 & 3 & 4 & 5 & 6 \\ \begin{array}{c}\text { Completely } \\ \text { Disagree }\end{array} & & & \text { Unsure } & & & \begin{array}{c}\text { Completely } \\ \text { Agree }\end{array}\end{array}$

1. My pain is caused by physical activity.

2. Physical activity makes my pain worse.

3. Physical activity might harm my back.

4. I should not do physical activities which (might) make my pain worse.

5. I cannot do physical activities which (might) make my pain worse.

The following statements are about how your normal work affects or would affect your back pain:

6. My pain was caused by my work or by an accident at work.

7. My work aggravated my pain.

8. I have a claim for compensation for my pain.

9. My work is too heavy for me.

10. My work makes or would make my pain worse.

11. My work might harm my back.

12. I should not do my normal work with my present pain.

13. I cannot do my normal work with my present pain.

14. I cannot do my normal work till my pain is treated.

15. I do not think that I will be back to my normal work within 3 months.

16. I do not think that I will ever be able to go back to that work. 
BRIEF ASSESSMENT OF DISTRESS AND PAIN

\section{Appendix $\mathrm{H}$}

Fear Questionnaire, Marks \& Mathews - Agoraphobia Subscale (FQ-Ag)

Choose a number from the scale below to show how much you would avoid each of the situations listed below because of fear or other unpleasant feelings. Then write the number you chose in the space to the left of each situation.

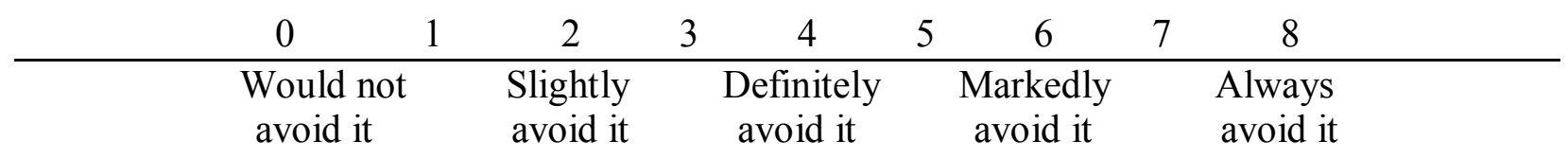

1. Travelling alone by bus or coach.

2. Walking alone in busy streets.

3. Going into crowded shops.

4. Going alone far from home.

5. Large open spaces. 
BRIEF ASSESSMENT OF DISTRESS AND PAIN

Appendix I

Demographics Form - Undergraduate Version

NAME: Today's date:

1. Age

How old are you?

2. Ethnicity / Race

What is your race or ethnicity?

\section{Education Level}

What is the highest level of education you completed?

\section{Romantic Relationship Status}

Single (no current romantic partner)

Married/Live with current partner

Current partner lives outside the home

Separated / Divorced / Widowed

\section{Current Employment Status}

Full-time employment

Part-time employment

Unemployed

Disabled

Volunteer

Other: 
BRIEF ASSESSMENT OF DISTRESS AND PAIN

\section{Current Occupation}

Not applicable (N/A)

Student

Skilled trade

Unskilled trade

Homemaker

Professional (specify:

Other:

7. What is your (combined) annual household income (before taxes)?

8. Are you undergoing any current counseling or other outpatient treatment for emotional or psychological problems?

Yes No

9. Have you ever had any previous counseling or other outpatient treatment for emotional or psychological problems?

Yes No

10. Have you ever been hospitalized for emotional or psychological problems?

Yes No

11. Are you currently taking any medications?

Yes $\quad$ No

If "Yes", please specify your medication(s) and dosage _ \# times taken per day here:

12. Do you have any current or past significant medical conditions?

Yes No

If "Yes", please specify your significant current or past medical condition(s) here: 
BRIEF ASSESSMENT OF DISTRESS AND PAIN

13. What is your (combined) annual household income (before taxes)?

$\$ 0-20,000$

$\$ 20-40,000$

$\$ 40-60,000$

$\$ 60-80,000$

$\$ 80-100,000$

$\$ 100,000$

P1) YES NO Do you now have significant pain that has lasted 6 months or more?

If NO, skip to P2

How severe would you rate that pain, on a scale from 0 - 100 with 0 being "no pain" and 100 being "the maximum pain possible"?

How long has this pain lasted? (convert to months)

How many days a week do you experience this pain?

What is the source of this pain?

Do you have any other significant pain now that has lasted 6 months or more? (Ask the same follow up questions, and repeat this cycle until the participant reports no more current chronic pain, then move to P2) 
BRIEF ASSESSMENT OF DISTRESS AND PAIN

P2) YES NO (Besides any pain just discussed) Have you ever had significant pain If NO, skip to P3 lasting 6 months or more?

How severe would you rate this pain, on a scale from 0 - 100, with 0 being "no pain" and 100 being "the maximum pain possible"?

How long did this pain last?____ (convert to months)

How many days a week did you experience this pain?

What was the source of this pain?

Have you had any other significant pain that has lasted 6 months or more? (Ask the same follow up questions, and repeat this cycle until the participant reports no more past chronic pain, then move to P3)

P3) YES NO Do you now have significant pain that has lasted less than 6 months?

If NO, skip to P4

How severe would you rate that pain, on a scale from $0-100$ with 0 being "no pain" and 100 being "the maximum pain possible"?

How long has this pain lasted?____ (convert to weeks)

How many days a week do you experience this pain?

What is the source of this pain? 
Do you have any other significant pain now that has lasted less than 6 months? (Ask the same follow up questions, and repeat this cycle until the participant reports no more current acute pain, then move to P4)

P4) YES NO (Besides any pain just discussed) Have you ever had significant pain

If NO, skip to lasting less than 6 months?

MED question

How severe would you rate this pain, on a scale from 0 - 100, with 0 being "no pain" and 100 being "the maximum pain possible"?

How long did this pain last? (convert to weeks)

How many days a week did you experience this pain?

What was the source of this pain?

Have you had any other significant pain that has lasted less than 6 months? (Ask the same follow up questions, and repeat this cycle until the participant reports no more past acute pain, then move to MED question) 
BRIEF ASSESSMENT OF DISTRESS AND PAIN

\section{Appendix J}

Demographics Form - Pain Sample Version

Participant ID \#: Date:

1. Age:

2. Sex (circle)

Male

Female

2. Ethnicity / Race (circle)

Caucasian/White

African-American/Black

Hispanic/Latino

Asian-American

American Indian/Alaskan Native

Other

Mixed

If answered you OTHER or MIXED, please describe.

\section{Educational Level}

How many years of formal education have you completed? (High school = 12 years; 4 year Bachelor's college degree $=16$ years, etc.) 
BRIEF ASSESSMENT OF DISTRESS AND PAIN

4. Marital / Relationship Status (circle)

Single (no current romantic partner)

Married/Live with current partner

Current partner lives outside the home

Separated

Divorced

Widowed

\section{Current Employment Status (circle)}

Full-time employment

Part-time employment

Unemployed

Disabled, not working

Volunteer

Other: (describe:

6. Occupation (either current, or the type of job you have had most of your life) (circle)

Student

Skilled trade

Unskilled trade

Homemaker

Professional (specify:

Other: (specify:

7. What is the combined annual income for everyone living in your household (before taxes)? (circle)

$\$ 0-20,000$

$\$ 20-40,000$

\$40-60,000

\$60-80,000

$\$ 80-100,000$

$\$ 100,000$ or more 
BRIEF ASSESSMENT OF DISTRESS AND PAIN

8. Are you undergoing any current counseling or other outpatient treatment for emotional or psychological problems? (circle)

Yes $\quad$ No

9. Have you ever had any previous counseling or other outpatient treatment for emotional or psychological problems? (circle)

Yes $\quad$ No

10. Have you ever been hospitalized for emotional or psychological problems? (circle)

Yes No

11. In general, would you say your health is: (circle)

Excellent

1

Very Good

Good

3

Fair

4

Poor

5

12. Are you currently taking any medications? (circle)

Yes No

If "Yes", please specify your medication(s) and dosage _ \# times taken per day here:

\begin{tabular}{|l|l|l|}
\hline Medication & Dose & \# Times per Day \\
\hline & & \\
\hline & & \\
\hline & & \\
\hline & & \\
\hline & & \\
\hline & & \\
\hline & & \\
\hline & & \\
\hline & & \\
\hline & & \\
\hline & & \\
\hline & & \\
\hline & & \\
\hline & & \\
\hline & & \\
\hline
\end{tabular}


BRIEF ASSESSMENT OF DISTRESS AND PAIN

\begin{tabular}{|l|l|l|}
\hline & & \\
\hline & & \\
\hline & & \\
\hline & & \\
\hline & & \\
\hline & & \\
\hline & & \\
\hline & & \\
\hline & & \\
\hline & & \\
\hline
\end{tabular}

13. Do you have any current or past significant medical conditions?

Yes No

If "Yes", please specify your significant current or past medical condition(s) here:

14. Have you ever had significant pain that has lasted 6 months or more? (circle)

Yes No

If "Yes", are you experiencing that pain now? (circle)

Yes $\quad$ No

If "Yes", how severe would you rate that pain, on a scale from 0 - 100 with 0 being "no pain" and 100 being "the maximum pain possible"? 
BRIEF ASSESSMENT OF DISTRESS AND PAIN

How long has the pain lasted?

years
months

How many days a week do you (or did you) experience this pain? (circle)

0

1

2

3

4

5

6

7

What is the cause of the pain?

15. Have you ever had significant pain that has lasted less than 6 months? (circle)

Yes No

If "Yes”, are you experiencing that pain now? (circle)

Yes $\quad$ No

If "Yes", how severe would you rate that pain, on a scale from 0 - 100 with 0 being "no pain" and 100 being "the maximum pain possible"?

How long has the pain lasted?

months 
BRIEF ASSESSMENT OF DISTRESS AND PAIN

How many days a week do you (or did you) experience this pain? (circle)

$\mathbf{0}$
1
2
3
4
5
6
7

What is the cause of the pain? 
BRIEF ASSESSMENT OF DISTRESS AND PAIN

\title{
Appendix K
}

\author{
Additional Reliability Items - Undergraduate Sample
}

1. To show that you are reading this item, please select the second response option below. Never

Sometimes

Occasionally

Always

*Appeared after the FPQ-III

2. Please select strongly disagree from the listed answer options. (Validity Item)

Strongly disagree

Disagree

Agree

Strongly Agree

*Appeared after the ASI-3

3. Please enter the following code into the answer box: Xq3F5jL

*Appeared after the FABQ

*Note. Item 3 was shown to not be effective in discriminating among consistent and inconsistent responses thus was not utilized for determination of reliability for the undergraduate sample. 